\title{
General and Prospective Views on Oxidation Reactions in Heterogeneous Catalysis
}

\author{
Sabine Valange ${ }^{1, *}$ and Jacques C. Védrine ${ }^{2, *} *$ (D) \\ 1 Institut de Chimie, des Milieux et Matériaux de Poitiers (IC2MP), UMR CNRS 7285, Université de Poitiers, \\ ENSI Poitiers, B1, 1 rue Marcel Doré, TSA41105, F-86073 Poitiers Cedex 9, France \\ 2 Sorbonne Université, Faculté des Sciences et Ingénierie, Laboratoire de Réactivité de Surface, \\ UMR-CNRS 7197, 4 place Jussieu, F-75252 Paris, France \\ * Correspondence: sabine.valange@univ-poitiers.fr (S.V.); jacques.vedrine@sorbonne-universite.fr (J.C.V.); \\ Tel.: +33-5-49454048 (S.V.); +33-1-44275560 (J.C.V.)
}

Received: 12 September 2018; Accepted: 18 October 2018; Published: 22 October 2018

check for updates

\begin{abstract}
In this review paper, we have assembled the main characteristics of partial oxidation reactions (oxidative dehydrogenation and selective oxidation to olefins or oxygenates, as aldehydes and carboxylic acids and nitriles), as well as total oxidation, particularly for depollution, environmental issues and wastewater treatments. Both gas-solid and liquid-solid media have been considered with recent and representative examples within these fields. We have also discussed about their potential and prospective industrial applications. Particular attention has been brought to new raw materials stemming from biomass, as well as to liquid-solid catalysts cases. This review paper also summarizes the progresses made in the use of unconventional activation methods for performing oxidation reactions, highlighting the synergy of these technologies with heterogeneous catalysis. Focus has been centered on both usual catalysts activation methods and less usual ones, such as the use of ultrasounds, microwaves, grinding (mechanochemistry) and photo-activated processes, as well as their combined use.
\end{abstract}

Keywords: heterogeneous catalytic oxidation; gas-solid; liquid-solid; partial and total oxidation; biomass based raw materials; activation methods

\section{Introduction}

Oxidation reactions cover a large part of the heterogeneous catalysis field and play a key role in a wide range of industrial reactions and processes, mainly in petrochemistry. Both selective and total oxidation reactions of organic compounds are concerned, such as those leading to aldehydes, ketones, carboxylic acids, nitriles, or for depollution purposes (pollutants degradation/removal), respectively. This field involves both gas-solid and liquid-solid media, the solid being the catalyst.

Nanoparticles with sizes of a few nanometers present high catalytic efficiencies due to higher surfaces available to reactants. They are often supported on metal oxides or on active carbons, which may lead to a determining role in the synergistic activation of substrates, in the electron conductivity changes, in the enhancement of redox reactions, in improving thermal conductivity, particularly useful for exothermal reactions in industrial processes to avoid overheating of the catalysts during the reaction. The activity, selectivity, resistance to deactivation and ability for regeneration are properties of paramount importance especially at the industrial level. The catalysts covered in this review are mainly nanostructured single and mixed metal oxides or the corresponding supported counterparts, as well as noble metals such as silver for epoxidation reactions, Pt for total oxidation reactions or gold and its alloys for liquid phase aerobic selective oxidation reactions (glycerol or allyl alcohols conversions). Enzyme-based catalysts also constitute a promising biocatalysis approach for 
future developments, whereas biomass and biomass-derived products constitute new raw material resources for future applications, mainly in liquid phase media.

The purpose of this review is to give a concise and representative view of recent developments in the field of partial and total oxidation reactions in gas phase and liquid phase. The review is organized in two main sections. The discussion starts with the case of selective oxidation reactions in gas phase (Section 2.1), then in liquid phase (Section 2.2). Section 2.3 has been first dedicated to the beneficial role of unconventional activation methods (namely, sonochemistry, microwave, mechanochemistry, electrochemistry and photochemistry) in enhancing liquid phase selective catalytic oxidation reactions, through representative cases. Then, the discussion moves to the use of such physical activation technologies for the development of greener synthetic routes for designing catalytic materials with controlled characteristics and improved catalytic properties for the selective oxidation of alcohols to the corresponding aldehydes or carboxylic acids. The second main section deals with total oxidation reactions in gas phase and liquid phase. At this point (Section 3.1), gas phase-solid catalyst total oxidation for depollution treatment is presented with a large part devoted to the case of atmospheric pollutants, such as industrial volatile organic compounds (VOCs) and/or highly diluted VOCs. Hybrid treatments combining catalytic oxidation with other technologies (e.g., light, ozonation, and non-thermal plasma) have also been developed. The review ends with the degradation of organic pollutants in liquid phase with a focus on advanced oxidation processes (Section 3.2).

Since our analysis cannot be overlong, the authors hope to provide informative and insightful representative examples on partial and total oxidation reactions in heterogeneous catalysis. Readers are also encouraged to refer to the cited review articles for additional in depth information.

\section{Selective Oxidation Reactions in Gas Phase and Liquid Phase}

\subsection{Gas Phase-Solid Catalyst Selective Oxidation Reactions}

This domain has led to the development of many industrial processes, mainly in the petrochemistry field, since the 1960s with the use of bismuth molybdate based catalysts for the oxidation of propene to acrolein and its ammoxidation to acrylonitrile by Sohio researchers [1]. This process has been recently reviewed by Brazdil [2,3], whereas the whole heterogeneous catalytic selective oxidation field has been reviewed recently by López Nieto [4] and Dagnan [5]. Such reactions proceed, the majority of the time, by the so-called Mars and van Krevelen (MvK) [6] redox-type mechanism schematized below in Equations (1) and (2) and was found to obey the seven-pillar rule as defined by Grasselli [7,8], namely:

- Nature of lattice oxygen anions, being either nucleophilic (partial oxidation) or electrophilic (total oxidation)

- Redox properties of the metal oxide (reduction of the cation with subsequent removal of lattice oxygen anions and their rapid reinsertion by oxygen from the gas phase) characterized by TPR and TPO methods

- Structure of the oxide should allow the redox mechanism to occur, without the collapse of the crystalline structure

- Phase cooperation, which facilitates electron transfer, thus enhances electrical conductivity, lattice oxygen anions mobility and the MvK redox mechanism

- Multifunctionality, such as $\alpha-\mathrm{H}$ abstraction and $\mathrm{O}-/ \mathrm{NH}$ - insertion in the organic molecule

- Active site isolation, to avoid a too high lattice surface oxygen anions mobility and thus over-oxidation to $\mathrm{CO}_{2}$

- $\quad \mathrm{M}-\mathrm{O}$ bond strength, which should be neither too weak (total oxidation) nor too strong (inactivity) (Sabatier's principle). 
This MvK mechanism takes place when the catalyst contains transition metal cations, which may change their oxidation state, such as $\mathrm{Ce}, \mathrm{Co}, \mathrm{Cr}, \mathrm{Cu}, \mathrm{Fe}, \mathrm{Mo}, \mathrm{Nb}, \mathrm{Ni}, \mathrm{Ti}, \mathrm{V}$ or $\mathrm{W}$, according to:

$$
\begin{gathered}
2[\text { CatO }]+\mathrm{R}-\mathrm{CH}_{3} \rightarrow 2[\text { Cat }]+\mathrm{R}-\mathrm{CH}=\mathrm{O}+\mathrm{H}_{2} \mathrm{O} \\
2[\text { Cat }]+\mathrm{O}_{2 \text { (gas) }} \rightarrow 2[\text { CatO }]
\end{gathered}
$$

In this scheme, [CatO] corresponds to the oxidized surface and [Cat] to its reduced state.

The main catalysts used industrially [9] are bismuth molybdate-based oxides since the pioneered work by researchers at Sohio in the 1960s, e.g., multicomponent catalysts such as BiMo-O $+\mathrm{CoFeMoO}_{4}$ for propene oxidation/ammoxidation to acrolein, acrylic acid/acrylonitrile; vanadyl pyrophosphate $(\mathrm{VO})_{2} \mathrm{P}_{2} \mathrm{O}_{7}$ catalyst, designated as $\mathrm{VPO}$, for butane direct oxidation to maleic anhydride; $\mathrm{MoVTe}(\mathrm{Sb}) \mathrm{Nb}-\mathrm{O}$ oxides (in particular those referred to as $\mathrm{M} 1$ and $\mathrm{M} 2$ phases) for direct conversion of propane to acrylonitrile or acrylic acid; iron phosphate-based catalysts for oxidative dehydrogenation of isobutyric acid to methacrylic acid; iron molybdate $\left(\mathrm{FeMO}_{4}\right)$ for oxidation of methanol to formaldehyde; $\mathrm{V}_{2} \mathrm{O}_{5} / \mathrm{TiO}_{2}$ for o-xylene oxidation to phthalic anhydride; benzene oxidation to phenol on titanosilicalite MFI zeolite (TS1); and MoVNb-O for ethane oxydehydrogenation (ODH) to ethene or its oxidation to acetic acid. For the selective oxidation of light alkanes, vanadium element appears as a major constituent of many active catalysts [10,11].

Recently, new mixed metal oxides have been proposed for gas phase selective oxidation reactions. For instance, bronzes A-M-B-O $\left(\mathrm{A}=\mathrm{NH}_{4}{ }^{+}, \mathrm{H}^{+}\right.$, alkali or alkali-earth cations; $\mathrm{M}=\mathrm{Mo}$ and/or, $\mathrm{W}$; $\mathrm{B}=\mathrm{V}$ and / or $\mathrm{Nb}$ ) with different types of channels in the ab plane, and grown along the c plane, have been proposed [12] for the ODH of ethane to ethylene and selective oxidative of ethanol to acetaldehyde [13]. One step glycerol oxydehydration to acrylic acid [14] was studied on a series of $\mathrm{Mo}_{3} \mathrm{VO}_{x} / \mathrm{H}_{4} \mathrm{SiW}_{12} \mathrm{O}_{40} / \mathrm{Al}_{2} \mathrm{O}_{3}$ catalysts. It was observed that acetic acid was produced in parallel with acrylic acid, at similar yield, vs. $\mathrm{Mo}_{3} \mathrm{VO}_{x}$ content. Crystallinity of $\mathrm{Mo}_{3} \mathrm{VO}_{x}$ was observed to increase with calcination temperature from 350 to $650{ }^{\circ} \mathrm{C}$, while a large amount of $(\mathrm{V}, \mathrm{Mo}) \mathrm{O}_{x}$ hetero-polyoxo mixed oxides was formed above $550{ }^{\circ} \mathrm{C}$. The Keggin structure of $\mathrm{H}_{4} \mathrm{SiW}_{12} \mathrm{O}_{40}$ was observed to dissociate near $450^{\circ} \mathrm{C}$, causing the formation of various $\mathrm{WO}_{x}$ species, while the yield of acrylic acid dropped and acrolein formation reached its maximum value, and the yield of acetic acid remained almost the same. These temperature effects show the importance of activation conditions. In the oxidative conversion of glycerol, both acidic and redox properties of catalysts were shown to have to be controlled. Moreover, it was also reported that both $\mathrm{W}-\mathrm{V}-\mathrm{O}$ and $\mathrm{W}-\mathrm{V}-\mathrm{Nb}-\mathrm{O}$ catalysts are active for methanol oxidative transformation to formaldehyde and dimethyl ether (DME). Catalytic performance of lanthanum vanadate $\left(\mathrm{La}_{0.1} \mathrm{~V}_{0.9} \mathrm{O}_{x}\right)$ catalyst in the ammoxidation of 2-methylpyrazine (MP) to 2-cyanopyarazine $(\mathrm{CP})$ has also been investigated [15].

The recent developments in the field of catalytic partial oxidation of ethane to oxygenated products have been comprehensively reviewed [16]. Moreover, the comparative catalytic oxidation of alcohols in both gas phase and liquid phase over size-controlled Pt nanoparticles was reviewed very recently [17].

\subsection{Liquid Phase-Solid Catalyst Selective Oxidation Reactions}

Utilization of resources other than fossil resources is essential for overcoming environmental issues and for a more sustainable world. One candidate for such resources is biomass, in particular sugars and lignocellulosic biomass (lignin, hemicellulose and cellulose fractions). Conversion of biomass and biomass-derived products has been studied extensively in the past three decades for the production of high added value products. Biodiesel synthesis and utilization of glycerol, its main by-product, are also important topics, already largely studied worldwide in the past ten years. It has indeed been widely reported that biodiesel represents an interesting and promising option for theoretical carbon zero overall consumption reactions. However, the biodiesel production leads to large amounts of glycerol, co-produced by conventional trans-esterification reaction, which has significantly impacted the glycerin market, and has made glycerol a low-cost raw material for conversion into high value 
chemicals and a key element for bio-based chemical industry [18]. Currently, only one process has

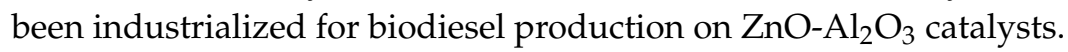

Among the different possibilities for glycerol conversion, its dehydration into acrolein has been proposed [12]. Acrolein is produced primarily by the gas-phase oxidation of propylene, as reminded above. However, as the use of propylene, particularly for the synthesis of polypropylene, has largely increased in the last decade, and this will continue, the availability and cost of propylene will increase. Catalysts and processes have then been developed for the direct conversion of glycerol to acrolein by simple dehydration on acid catalysts [19]. However, in such processes, there are two major drawbacks: (i) deactivation; and (ii) selectivity limited to $80 \%$. There is thus a need for the development of novel routes for the production of acrolein, such as the conversion of allyl alcohol, produced by fermentation or dehydration of 1,3-propanediol or dehydration/oxidation of glycerol [19]. Glycerol or allyl alcohol partial oxidation to dihydroxyacetone and to acrylic acid have also been largely studied and published in the open literature [20-24]. Oxidehydration of glycerol into acrylic acid has been reported using multifunctional catalysts able to carry out in a single-step transformation its dehydration to acrolein and further oxidation into acrylic acid, both in gaseous and liquid phases [17]. Vanadium-containing tungsten oxide bronzes $\left(\mathrm{W}_{1-\mathrm{x}} \mathrm{M}_{\mathrm{x}} \mathrm{O}_{\mathrm{z}}\right.$ catalysts; $0<\mathrm{x}<0.33, \mathrm{M}$ : $\left.\mathrm{Nb}, \mathrm{V}\right)$ constitute one of the most promising catalytic systems to perform the one-pot oxidehydration of glycerol to acrylic acid $[14,25,26]$. An enhanced catalytic behavior for KIT- 6 mesoporous silica supported $W_{1-x} M_{x} O_{z}$ catalyst has been observed for that reaction, in which an increase in the yield to acrylic acid $(31 \%)$ is observed compared with the unsupported catalyst (19\%). This improvement has been ascribed to both the effect of the support, the size of bronze particles and the specific vanadium species. It was observed that bulk W-V-O bronze exhibits a higher concentration of acid species on the surface than when supported on a mesoporous silica.

The liquid phase selective transformation of oxygenated compounds in aqueous effluents is an important objective in the development of biorefineries. For instance, oxidative esterification of furfural with methanol to methyl 2-furoate used as fragrance component has been studied on gold on $\mathrm{ZrO}_{2}, \mathrm{CeO}_{2}, \mathrm{TiO}_{2}$ or $\mathrm{Fe}_{2} \mathrm{O}_{3}$ supports [27-29]. Furfural is one of the top value-added biomass-derived chemicals [30], and has already commercial applications in the chemical industry.

Oxidative esterification of biomass-derived furans, such as furfural and 5-hydroxymethylfurfural (HMF) to the corresponding esters, was also successfully performed over non-precious metal catalysts, namely cobalt-based carbon-supported catalysts obtained after pyrolysis of a Co complex adsorbed on activated carbon [31]. Among the biomass-derived chemical building blocks, 2,5-furan dicarboxylic acid (FDCA) is considered as a key near market platform chemical, as it is expected to replace terephthalic acid in various polyesters. The traditional synthesis of FDCA from HMF requires hard conditions and weak atom efficiency during its purification. As a greener alternative route, it was shown that $\mathrm{Au} /$ hydrotalcites can selectively lead to HMF aqueous phase aerobic oxidation to FDCA at low temperature, at high surface Au concentration [32]. Such aqueous phase aldehyde and alcohol cascade oxidations could also be carried out effectively over mixed $\mathrm{Mn}_{\mathrm{x}} \mathrm{Fe}_{\mathrm{y}}$ oxide catalysts under mild reaction conditions [33].

The production of value-added organic acids by selective oxidation of biomass resources is also of great importance in the chemical industry. Transition metal oxides, such as $\mathrm{CuO}$, have been used for the selective conversion of glucose to lactic acid and acetic acid under hydrothermal conditions [34], while mixed metal oxides of the perovskite-type can be used for the conversion of a variety of cellulosic biomass [35]. The authors have shown that the redox properties of the $\mathrm{LaCoO}_{3}$ catalyst are key parameters in the conversion of glucose, xylose and cellulose to lactic acid in water under subcritical conditions. In a very recent study, it was reported that the finely tuned combination of solvents and solid catalysts improves the production of di-acids from biomass [36]. $\gamma$-valerolactone (GVL), as renewable co-solvent, allows the conversion of biomass to furfural and its direct upgrading to maleic acid in high yield and at low reaction temperatures in the presence of titanium silicalite (TS-1) and $\mathrm{H}_{2} \mathrm{O}_{2}$. Deactivation of the catalyst was prevented due to the presence of GVL as 
co-solvent which avoids insoluble heavy by-product deposits on the catalyst, improving its long-term stability. Hence, the catalyst could be reused for 17 successive runs without detectable deactivation, whereas deactivation occurred when the reaction was performed in water. Several perovskites metal oxides $\left(\mathrm{LaMnO}_{3}, \mathrm{LaCoO}_{3}, \mathrm{LaFe}_{1-\mathrm{x}} \mathrm{Cu}_{\mathrm{x}} \mathrm{O}_{3}\right.$, etc.) were also shown to efficiently catalyze the wet aerobic oxidation of lignin to aromatic aldehydes [37].

In addition to many metal oxide catalysts, one may cite heteropoly-oxometallates (POMs) of Keggin or Dawson types, micro- or mesoporous metal oxides, such as the MOFs family (Figure 1) as tentative new catalysts for epoxidation reactions in liquid phase [38] and even inclusion of POM in MOF [39] in selective oxidation reactions in liquid phase [40-42].

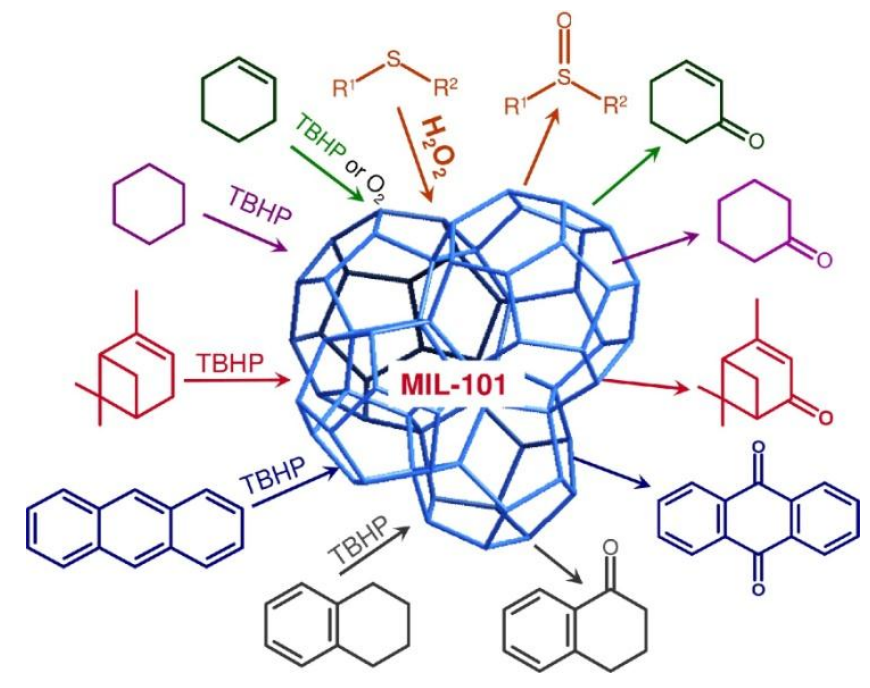

Figure 1. Oxidation reactions performed on Cr-MIL-101 MOF catalysts [40].

Regarding the nature of the oxidizing agent and, in particular the case of hydrogen peroxide, its direct synthesis in-situ has already been investigated at ambient temperature starting from $\mathrm{H}_{2}$ and $\mathrm{O}_{2}$ in the presence of various supported noble metal-based catalysts [43]. In a very recent report, direct synthesis of $\mathrm{H}_{2} \mathrm{O}_{2}$ in water over $\mathrm{Pd} / \mathrm{TiO}_{2}$ catalysts was examined in a continuous flow reactor setup at ambient temperature and elevated pressures [44]. Under reaction conditions, the supported Pd nanoparticles were inactive when covered by chemisorbed oxygen, but when hydrogenated they were able to form palladium hydride, as revealed by operando XAS studies. This hydride can form $\mathrm{H}_{2} \mathrm{O}_{2}$ for $\mathrm{H}_{2} / \mathrm{O}_{2}$ ratio $<2.0$ under pressure $(1 \mathrm{MPa})$. Actually, propene epoxidation with $\mathrm{H}_{2} \mathrm{O}_{2}$ produced in situ from $\mathrm{H}_{2}$ and $\mathrm{O}_{2}$ gases has already reached a commercial level. All these results demonstrate that the rational design of catalysts and the optimization of the process parameters are key prerequisites for making the direct synthesis of $\mathrm{H}_{2} \mathrm{O}_{2}$ to be more widespread in industrial oxidation reactions.

Although major industrial processes were discovered and developed in the second half of last century, some progress and new findings are needed. The main challenge in catalysis for the future is to reach $100 \%$ selectivity and to use less energy. In this respect, unconventional activation methods based on ultrasound (US) and microwave (MW) irradiations, ball milling (reactive grinding), and electrochemical and photo-activated processes are viewed as "Green Chemistry" approaches to increase reaction rates, shorten reaction times while enhancing yields and selectivities. These aspects are discussed in the following section.

\subsection{Unconventional Activation Methods for Liquid Phase Selective Oxidation Reactions}

Unconventional activation methods are non-thermal processes/technologies that do not imply any external source of heating. Hence, the reaction can be activated either by: (1) the technology itself through the action of light, pressure, electric field, waves, etc.; or (2) the heat generated in situ. Such physical activation methods offer challenging opportunities for developing clean, selective and 
energy-efficient synthetic strategies for both the production of high value-added compounds [45,46] and pollutant abatement. Here, the synergy of these technologies with catalysis for selective oxidation reactions in liquid phase is emphasized through selected representative literature studies. Sonochemistry, microwave, mechanochemistry, electrochemistry and photochemistry have been chosen for the discussion.

Sonochemistry is a field of chemistry based on energy delivered by power ultrasound. The ultrasonic effects originate from the cavitation phenomenon, namely the rapid nucleation, growth and collapse of gaseous bubbles generated in the sonicated liquid. This sudden collapse is responsible for chemical effects (formation of radical species) and mechanical effects (shear forces, microjets, and shock waves), leading to the acceleration of organic reactions thanks to the mass transfer effect generated by sonication. Cavitation depends on external parameters such as the ultrasonic frequency, acoustic power, intensity, hydrostatic pressure, gas atmosphere, nature and temperature of the sonicated solvent, geometry of the reactor, etc.

The combination of ultrasonic waves and heterogeneous catalysts has proven to be a useful choice in selective conversions of organic substrates to value-added chemicals. The combined use of a nanostructured $\mathrm{Co}_{3} \mathrm{O}_{4}$ catalyst with ultrasonic irradiation $(19.95 \mathrm{kHz})$ enables the selective oxidation of a lignin-derived compound (vanillyl alcohol) to the corresponding aldehyde (vanillin) under milder conditions than under conventional heating in the absence of ultrasound irradiation [47]. The US-assisted reaction with $\mathrm{H}_{2} \mathrm{O}_{2}$ as $\mathrm{O}$-donor and water as solvent at ambient pressure proved to be faster $(4 \times)$, more selective $(2.3 \times)$, more performant $(2.7 \times)$ and more energy efficient $(8 \times)$ than the reaction performed under silent conditions. The results have been ascribed to enhanced chemical effects (production of $\mathrm{HO}^{\bullet}$ through in situ formation of $\mathrm{H}_{2} \mathrm{O}_{2}$ in the sonicated water) and physical effects (increased mass transfer) promoted by ultrasound on the catalyst surface. In another study, the oxidation of benzyl alcohol has been conducted in $\mathrm{CH}_{3} \mathrm{CN}$ in the presence of multi-walled carbon nanotubes supported on $\mathrm{TiO}_{2}$ in an ultrasonic bath working at $40 \mathrm{kHz}$ and $250 \mathrm{~W}$ at $25{ }^{\circ} \mathrm{C}$ [48]. The yield to benzaldehyde reached $100 \%$ within 15 min under these ultrasonic conditions, compared to that obtained for the reaction performed under silent conditions ( $45 \%$ after 20 min of reaction). Next, the selective conversion of a variety of substituted cyclic alcohols and alkenes to the corresponding aldehydes, ketones and epoxides under these optimized ultrasonic conditions led to excellent yields (93-99\%) within 15-20 min due to synergistic effects between the hybrid nanocatalyst and ultrasonic irradiation (i.e., increased number of molecular interactions leading to higher activities/yields, lowering of the activation energy of the rate limiting step and shorter reaction times). More examples about the coupling of ultrasonic waves and metal-based catalysts in targeted organic compounds synthesis, including oxidation reactions, can be found in the recent review by Domini et al. [49]. Although the application of ultrasonic irradiation in the field of selective oxidation reactions offers many advantages, the design of specific sonochemical reactors is however a key issue for large scale developments. One of the limitations is related to the inhomogeneity of the ultrasonic field in the whole medium and hence in the maximization of the cavitational efficiency (yield). The development of continuous flow sonochemical reactors is also a challenging issue to overcome to meet industrial needs.

Among the physical activation technologies able to promote fast chemical transformations, microwave is probably the most popular one. By absorbing the MW energy, the reaction mixture undergoes a rapid internal heating through the interaction of the electromagnetic irradiation with the molecules contained in the mixture.

In a recent work, the direct production of vanillin (and vanillic acid) from woody biomass has been carried out in a MW-assisted reaction using $\mathrm{CuO}$ and hydrogen peroxide [50]. The impact of the electric and magnetic fields of the microwave irradiation on the reaction yields have been determined by using a cavity resonator, which can separate both fields. The reaction has also been performed in the same reactor under the same heating conditions but under conventional heating for comparison purposes. Under microwave heating at $180{ }^{\circ} \mathrm{C}$ for $10 \mathrm{~min}$, the yield to vanillin and vanillic acid was three times higher than that obtained without MW irradiation (Figure 2). The higher production rate 
observed in the MW-assisted reaction than under conventional heating is due to both electric and magnetic fields (lower apparent activation energy values) with a slightly more prominent effect of electric fields, highlighting the MW-sensitive character of this reaction (Figure 2). As compared to previous works, this study highlighted for the first time the microwave effects on the production of lignin monomers from softwood particles, as well as its industrial feasibility as mentioned by the authors [50]. However, no information regarding the evaluation of the cost of this MW process was reported, although such technique is known to be energy demanding.

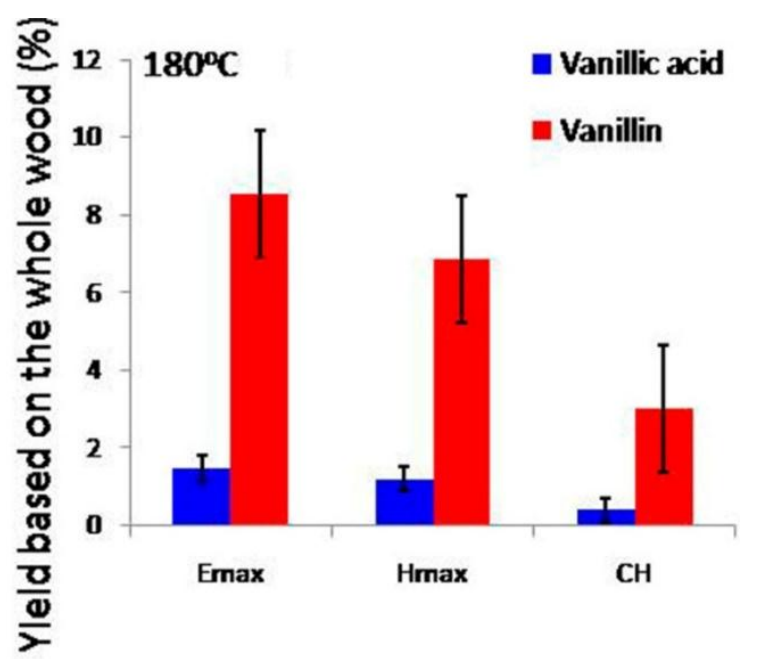

Figure 2. Comparison of the yields to vanillin and vanillic acid by microwave electric $\left(\mathrm{E}_{\max }\right)$ and magnetic $\left(\mathrm{H}_{\mathrm{max}}\right)$ effects and conventional heating $(\mathrm{CH})$ in a cavity perturbation heating system, adapted from [50].

Mechanochemistry also represents an alternative solvent-free route to traditional methods for selective transformation reactions. According to the IUPAC definition, mechanochemistry is the branch of solid-state chemistry where a chemical reaction is induced by the direct absorption of mechanical energy [51]. In a mechanochemical process, intramolecular bonds are broken during the reactive grinding of the reactants due to the mechanical action, leading to chemical reactions. The selective oxidation of a broad set of primary and secondary benzyl alcohols to the corresponding aldehydes and ketones has been recently performed at room temperature under solvent-free ball milling conditions with no trace of over-oxidation carboxylic acid products [52]. Under mechanical activation conditions with zirconia milling balls, higher rates/shorter reaction times $(2 \times 5-7 \mathrm{~min})$ could be obtained than with the classical TEMPO-based oxidation reaction (several hours to $24 \mathrm{~h}$ ). The mechanically-assisted oxidation of alcohols with alkyl or aryl substituents resulted in excellent product yields ranging from $90 \%$ to $98 \%$, as well as for secondary alcohols independently of the position or nature of the functional groups (same yield range). Additionally, the oxidation of 2-hydroxybenzyl alcohol to salicylaldehyde could also be achieved under these ball milling conditions (yield of $98 \%$ ) in contrast to the homogeneous TEMPO procedure. The scope of the reaction was also extended to the selective oxidation of alkynols to propargylic aldehydes, which are not available through traditional homogeneous oxidation routes. Phenylpropargylaldehyde could indeed be produced after four successive ball milling cycles of $15 \mathrm{~min}$ each, although in modest yield (39\%). This study emphasizes that reactive grinding constitutes a viable physical activation technology for the solvent-free conversion of a library of alcohols to aldehydes and ketones, provided the milling time is adequately defined. Otherwise, the decomposition of the desired products can occur under prolonged milling times due to the mechanical action [52]. Evaluation of the cost and energy consumption of these ball milling processes is however seldom taken into account in the reported literature studies. 
Electrocatalytic oxidation is another alternative approach for biomass valorization thanks to high activity coupled to low energy consumption [53]. For instance, a variety of carbohydrates could be transformed in electrochemical reactors under mild reaction conditions for the production of high value-added feedstocks. The electrocatalytic selective oxidation of cellulose to gluconate was reported on gold nanoparticles supported on a carbon aerogel (CA) used as anode in an alkaline medium [54]. Dissolution of cellulose in the $\mathrm{NaOH}$ solution promoted its hydrolysis, prior to its electrocatalytic conversion to gluconate on $\mathrm{Au} / \mathrm{CA}$ anode or eventually to oxalate for prolonged electrolysis times (Scheme 1). The gluconate yield reached $67.8 \%$ after $18 \mathrm{~h}$ of electrocatalytic oxidation.

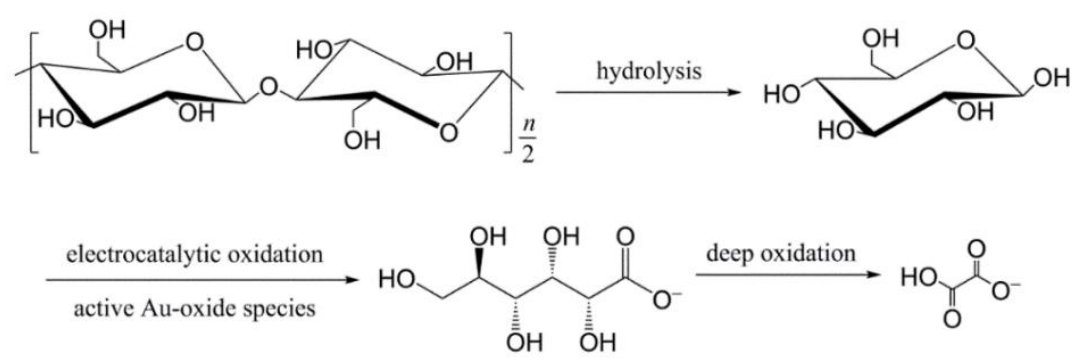

Scheme 1. Electrocatalytic oxidation of cellulose to gluconate [54].

Photocatalysis can also be used for the transformation of organic compounds into valuable products in liquid phase. The mechanism of this reaction follows three steps: (i) under UV-light, the absorption of photons by the photocatalyst creates an electron-hole $\left(\mathrm{e}^{-} \mathrm{h}^{+}\right)$pair when the photon energy is larger than that of the band gap; (ii) this $\mathrm{e}^{-} \mathrm{h}^{+}$pair migrates to the surface and is trapped by $\mathrm{OH}$ surface groups forming hydroxyl $(\mathrm{HO})^{\bullet}$, hydrosuperoxide $\left(\mathrm{HO}_{2}{ }^{\bullet}\right)$ and superoxide $\left(\mathrm{O}_{2}{ }^{\bullet-}\right)$ radicals; and (iii) the free radicals finally lead to the oxidation of the organic compounds.

Selective catalytic photo-oxidation of lignocellulose-based biomass are currently the subject of intensive research, since they can afford a variety of valuable compounds, including some sugar-derived platform chemicals (e.g., succinic, 5,5-furandicarboxylic, 3-hydroxypropionic, gluconic, glucaric and levulinic acids and 3-hydroxybutyrolactone) [55]. The photocatalytic selective conversion of alcohols can be performed as well, but the reaction efficiency depends on the type of alcohol. The oxidation of primary alcohols is generally low, but high selectivities can be achieved $(>95 \%)$. The initial step of the proposed mechanism is the interaction of a surface hole with the $\mathrm{OH}$ group of the alcohol, leading to metal-oxo species with proton removal. This step is easier for alcohols with increased carbon chain length and branching, and thus improved conversion can be achieved. Photocatalytic selective oxidation processes bring several benefits from environmental and energy viewpoints, notably by promoting milder conditions than under conventional thermal catalysis. However, photocatalysts with high activity/selectivity and stability have yet to be found, especially for the selective photoconversion of biomass in aqueous medium or under solvent-free conditions. The efficiency of photocatalysts in converting biomass to the target product could be limited by the conversion/selectivity ratio. Here, the main drawback is the control of the reaction pathway so as to avoid complete mineralization. More efforts should also be paid to the use of solar light irradiation in aqueous solution as a renewable source of energy for the heterogeneous selective photo-oxidation of a variety of biomass derivatives.

The combined use of sonochemistry (power ultrasound) and photocatalysis, called sonophotocatalysis, recently found innovative applications in organic compounds reactions and biomass conversion (lignin, chitosan, etc.) to high-added value intermediates [56]. Under coupled UV/US irradiations, an increased amount of radical species is produced in the reaction medium $\left(\mathrm{HO}^{\bullet}, \mathrm{O}_{2}^{\bullet}{ }^{\bullet-}\right.$, and $\left.\mathrm{HO}_{2}{ }^{\bullet}\right)$ in the presence of a catalyst. Additionally, turbulence induced by the cavitation phenomenon (US irradiation) also increases, resulting in a simultaneous increase of catalytically active surface area through deagglomeration of the particles and hence on an enhanced mass transfer between the catalyst surface and the liquid phase. These beneficial effects 
account for an overall increased catalytic activity compared to the individual approaches (Figure 3). Until now, sonophotocatalysis has been mainly applied as an advanced oxidation process for pollutant degradation purposes (see Section 3.2), but it is also considered as an innovative and promising tool for organic reactions and biomass valorization. Even if [...] the sonophotocatalytic technology is still in its infancy for the conversion of biomass and biomass-derived products to platform molecules, this is an avenue well worth exploring and [...]special attention should be paid in the near future to its implementation. Fundamental studies are indeed required to understand the mechanisms involved in sonophotocatalysis applied to selective oxidation reactions. Determination of the cavitation intensity and energy efficiency in these combined sonochemical and photocatalytic conditions is also essential prior to further applications in this area.

SONOCATALYSIS

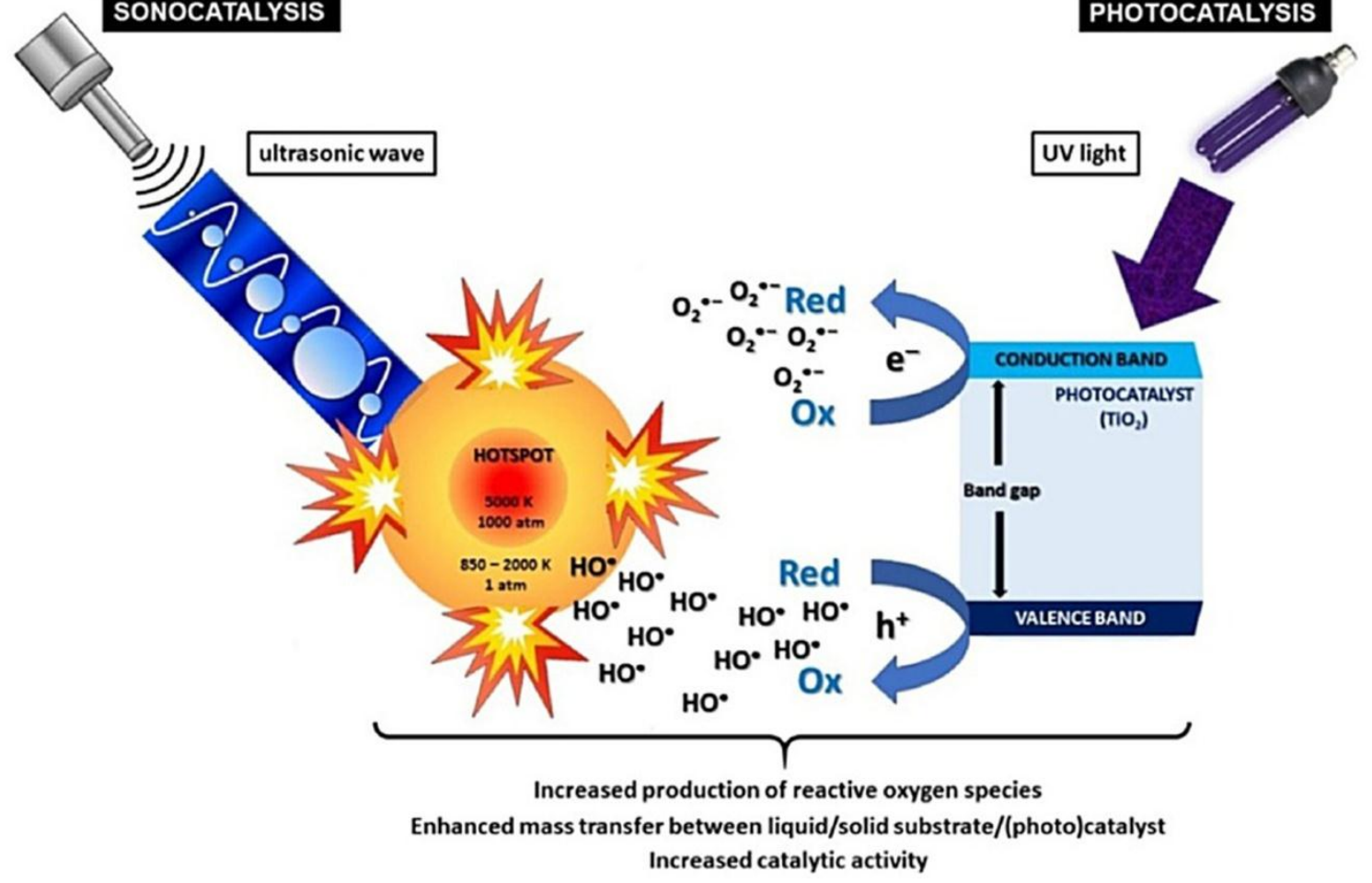

Figure 3. Schematic representation of the principle of sonophotocatalysis combining sonocatalysis and photocatalysis [56].

In line with the use of unconventional activation methods for selective catalytic oxidation reactions, non-thermal activation techniques can also be appropriately used for the development of greener and generalized synthesis routes for designing catalytic materials with controlled characteristics and improved activity and selectivity. Ultrasound and microwave irradiations, ball milling and sonophotodeposition, to name a few strategies, represent innovative technologies to the conventional solid-state, wet chemistry and gas phase synthesis procedures. Many review articles are available in the literature, offering a comprehensive discussion on this subject [57-61]. Here, through a few selected examples, we wish to highlight the advantages of using ultrasound, ball milling, sonophotodeposition and sonoelectrodeposition in the synthesis of solid catalysts (and photocatalysts) for the selective oxidation of alcohols to the corresponding aldehydes or carboxylic acids.

Ultrasound-assisted synthesis has been demonstrated to bring unexpected improvements in physical and physicochemical properties of metal oxides, such as particle size and shape control, high purity phase, and increased surface area, among others. Pure manganese octahedral molecular sieves (OMS-2) were synthesized by a direct sonochemical method at ambient temperature and pressure without any calcination step [62]. OMS-2 materials, exhibiting very high surface area $\left(288 \mathrm{~m}^{2} \mathrm{~g}^{-1}\right)$ and 
small particle sizes (1-7 nm), have been obtained after $2 \mathrm{~h}$ of irradiation in a water/acetone system, as compared to previously reported OMS-2 prepared under reflux conditions $\left(\mathrm{S}_{\mathrm{BET}}\right.$ of $88 \mathrm{~m}^{2} \mathrm{~g}^{-1}$ and particle sizes of $11.4 \mathrm{~nm}$ ). The sonochemically synthesized materials also possess greater amounts of surface defects and have shown enhanced catalytic activity in the selective oxidation of benzyl alcohol to benzaldehyde (TON of 8.32) compared to conventionally prepared OMS-2 catalysts (TON of 3.36). Highly pure and crystalline $2 \mathrm{D} \mathrm{CuO}$ nanoleaves have been synthesized at $25^{\circ} \mathrm{C}$ under low frequency ultrasound $(19.95 \mathrm{kHz}, 8.2 \mathrm{~W}$ electric power) and further used in the base-free aqueous oxidation of glycerol to dicarboxylic acids in the presence of hydrogen peroxide under mild reaction conditions [63]. The significant advantages of this sonochemical preparation route over conventional methods include a direct synthesis, incredibly fast experiments (5 min), non-thermal activation and in situ pseudo-calcination. Additionally, the $\mathrm{CuO}$ nanoleaves, prepared by the reported technique, have been observed to be more active, selective and robust (against leaching) than the corresponding nanoleaves prepared without ultrasound irradiation. Readers are also referred to the review by Domini et al. [49] for other examples of sonochemically-generated catalysts for various oxidation reactions.

Mechanochemically prepared catalysts can also display improved features over catalysts obtained through more traditional synthesis procedures, which are in many cases not environmentally friendly. The group of Luque has extensively used the one-step mechanochemical ball milling route to prepare a wide range of nanomaterials for catalysis and energy application purposes [59], namely supported metal or metal oxide nanoparticles, mixed oxides, nanocomposites and MOFs (Figure 4). A series of mesoporous silica supported iron oxide nanoparticles were prepared by ball-milling and their catalytic properties were investigated in the selective oxidation of various alcohols with $\mathrm{H}_{2} \mathrm{O}_{2}$ [64]. Under optimum conditions (dry milling, $350 \mathrm{rpm}, 10 \mathrm{~min}$ ), the ball-milled catalysts consisting of low iron loaded Al-SBA-15 materials showed a higher catalytic activity in the microwave-assisted oxidation of benzyl alcohol to the corresponding aldehyde with respect to Fe/Al-SBA-15 counterparts prepared by a conventional impregnation method.

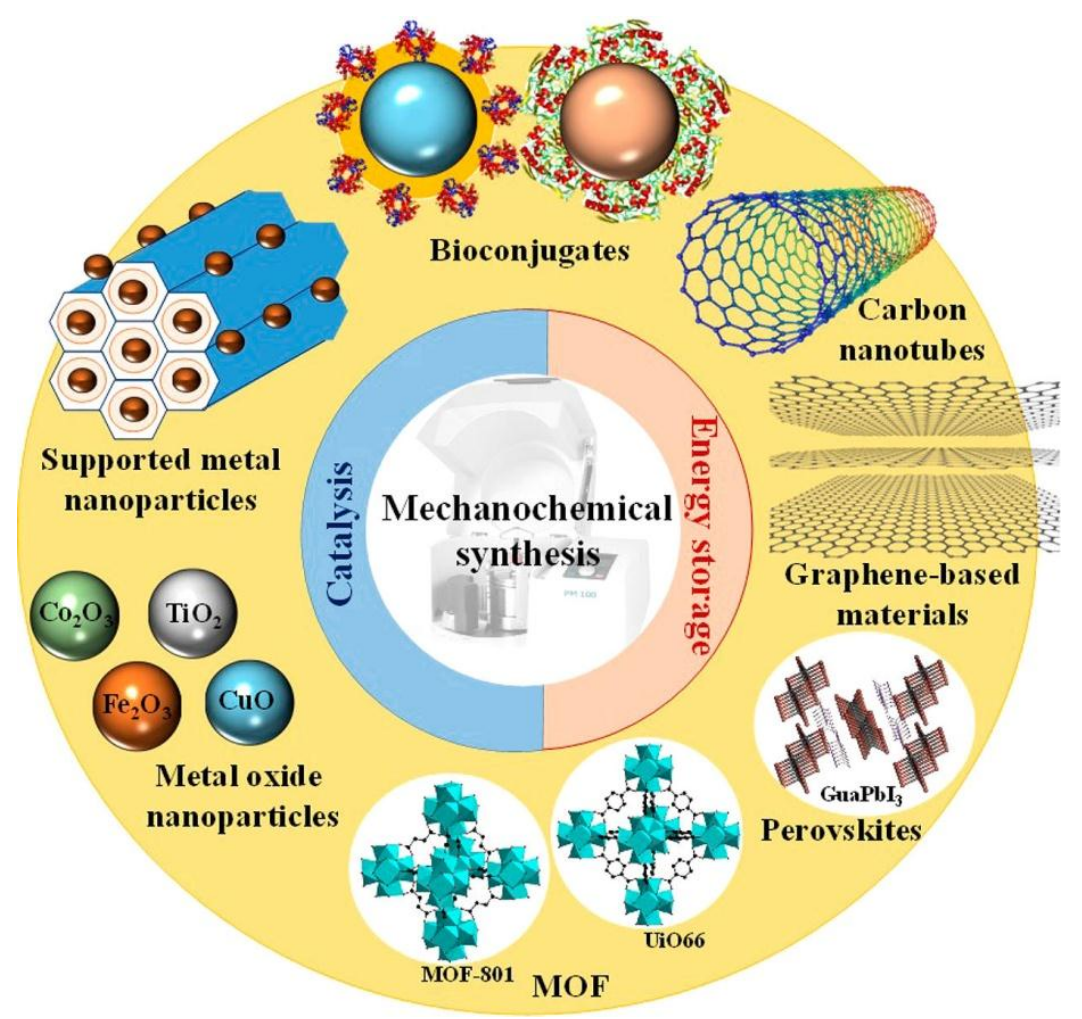

Figure 4. Schematic representation of advanced materials synthesized by a ball-milling route for catalytic and electrochemical energy storage applications [59]. 
Merging unconventional activation methods may also result in new powerful methodologies. In this sense, various materials with controlled morphology and composition have been produced by the in situ coupling of ultrasound with chemical (electrochemical and photochemical) deposition methods. The mechanism of sonoelectro- and sonophotodeposition processes is different (electrochemical reactions vs. photoexcitation), but their synergy with sonication is essentially based on the cavitation phenomenon [61]. The resulting enhanced mass transfer is generally seen as the increase of electrochemical current (or current pulses) in the case of the sonoelectrodeposition process, thereby leading to deposits with enhanced mechanical properties and electrocatalytic properties. In the sonophotodeposition method, the cavitation process influences the transfer of photoexcited states which results in enhanced photochemical reaction rates and then in deposits with improved chemical properties (Figure 5).

(1)

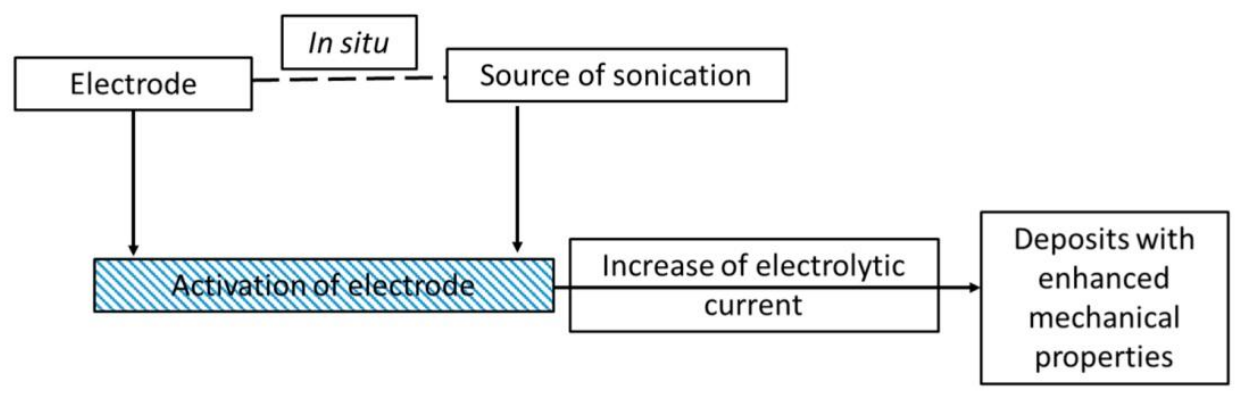

(2)

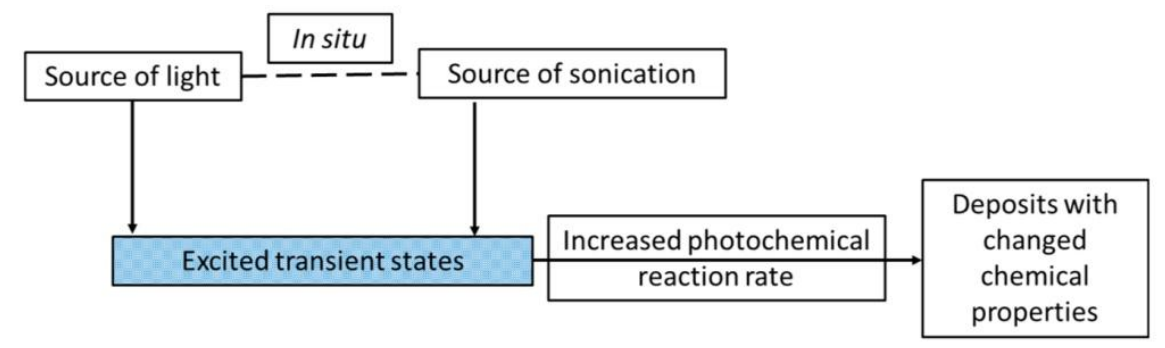

Figure 5. Schematic representation of the synthesis of materials by using the (1) sonoelectrodeposition and (2) sonophotodeposition processes, adapted from [61].

Single-step sonoelectrodeposition of CdS nanoparticles with homogeneous distribution inside $\mathrm{TiO}_{2}$ nanotubes (NTs) has been performed [65], leading to highly photoelectrochemically active materials (ultrasonic bath, $40 \mathrm{kHz}, 2.4 \mathrm{~kW} \mathrm{~m}^{-2}$, constant current density of $5 \mathrm{~mA} \mathrm{~cm}{ }^{-2}, 50{ }^{\circ} \mathrm{C}$ ). Most importantly, the tubular structure of the nanotubes was not damage by ultrasound irradiation during the $\mathrm{CdS}$ sonoelectrodeposition process. The resulting $\mathrm{CdS}-\mathrm{TiO}_{2} \mathrm{NTs}$ electrodes produced a stronger photocurrent coupled to an extended photoresponse under visible light compared to the corresponding electrodes prepared by the electrodeposition method in silent conditions (without ultrasonic irradiation). To date, only a few materials/catalysts have been prepared by the sonophotodeposition method that was implemented by the group of Colmenares [61]. For example, $\mathrm{Fe}^{3+}$-based nanoparticles $\left(4-5 \mathrm{~nm}\right.$ ) were sonophotodeposited on a $\mathrm{TiO}_{2} /$ zeolite $\mathrm{Y}$ support material (ultrasonic horn, $20 \mathrm{kHz}, 700 \mathrm{~W}, 25 \%$ amplitude, sun-imitating Xenon lamp, 240-2000 nm) [66]. The nanoparticles were found to be mainly located in the bulk of the photocatalyst due to the physical effect of ultrasound, with, as a consequence, better catalytic performances in the selective photo-oxidation of benzyl alcohol to benzaldehyde compared to the catalyst prepared by the ultrasound-assisted wet impregnation procedure.

The few examples given above describe what can be done with the use of non-thermal activation methods in the synthesis of catalytic materials, exhibiting controlled features and improved efficiencies, and demonstrate that more researches are needed, since new activation procedures are able to improve catalytic properties. 
The studies reported in recent literature regarding the use of ultrasound and microwaves irradiations, ball milling, electrochemical and photo-activated processes in selective oxidation reactions highlighted their beneficial role in enhancing the catalytic activity and yields while shortening reaction times. Synergistic effects have been clearly shown to occur when such physical activation methods are combined with catalysis for selective oxidation reactions in liquid phase. In the near future, more efforts are however needed to better describe the underlying mechanisms of these activated processes. Sufficient account must also be taken of the full description of the operating parameters to allow the comparison of results obtained with different processing conditions and/or devices. These essential considerations are often underestimated in the studies reported in the literature. Most importantly, the assessment of the economic impact of such hybrid processes should be systematically conducted in terms of cost and energy consumption for the comparison with classical thermal catalysis, and particularly prior to any scaling up developments.

\section{Total Oxidation Reactions in Gas Phase and Liquid Phase}

\subsection{Gas Phase-Solid Catalyst Total Oxidation Reactions}

This domain covers many reactions used for depollution treatments and combustion [67]. The main catalysts, used at present, are based on expensive noble metals, but many efforts have been carried out in the last two decades to replace them, in a number of processes, by much cheaper transition metal oxide-based catalysts $(\mathrm{M}=\mathrm{Ce}, \mathrm{Co}, \mathrm{Fe}, \mathrm{Mn}, \mathrm{Ni})$. For instance, perovskites $\left(\mathrm{LnBO}_{3}\right)$ in which $\mathrm{Ln}$ is a lanthanide (usually $\mathrm{La}$ ) and $\mathrm{B}$ a cation which possesses two valence states as $\mathrm{Co}$, $\mathrm{Fe}$ or $\mathrm{Mn}$, e.g., $\mathrm{La}_{1-\mathrm{x}} \mathrm{M}_{\mathrm{x}} \mathrm{MnO}_{3+\delta}$ with $\mathrm{M}=\mathrm{Ce}$ or $\mathrm{Sr}$, and also spinels, hexaaluminates and some other oxide structures have been proposed and studied. Hexaaluminates $\left(\mathrm{AB}_{\mathrm{x}} \mathrm{Al}_{12-\mathrm{x}} \mathrm{O}_{19-\delta}\right.$, where $\mathrm{A}$ and $\mathrm{B}$ are $\mathrm{a}$ lanthanide and a transition/noble metal cation, respectively), are formed of alternate layers of alumina spinel blocks and mirror planes in which a large A cation is located.

Single oxides have been shown to be active for total oxidation reactions $(\mathrm{CO}$, methane, VOCs, wet air oxidation, etc.), as well as for the treatment of nitrogen, chlorinated and sulfided compounds, in particular $\mathrm{NO}_{x}, \mathrm{NH}_{3}$, urea. Their activity for total oxidation has been suggested to be due to $\mathrm{Mn}^{+} / \mathrm{M}^{(\mathrm{n}+1)+}$ ion pairs associated with oxygen vacancies, and subsequent adsorption or heterolytic splitting of the molecule (CO, hydrocarbons) and for $\mathrm{O}_{2}$ activation. This is why oxides such as $\mathrm{Co}_{3} \mathrm{O}_{4}$ or $\mathrm{Fe}_{3} \mathrm{O}_{4}, \mathrm{Mn}$ - and $\mathrm{Cu}$-based oxides are appropriate candidates for oxidation reactions [68], even in the absence of a noble metal. For instance, $\mathrm{Cu}$ - or Fe-exchanged zeolites have been used in DeNOx processes, because of their stability above $900{ }^{\circ} \mathrm{C}$.

Volatile organic compounds (VOCs) are highly toxic atmospheric pollutants, arising from mobile sources and industrial emissions. Their degradation has then become a major area of concern in environmental protection. Common VOCs, namely hydrocarbons, halogenated hydrocarbons, ketones, alcohols and aromatic compounds, are emitted in many industrial factories in their throwing away emissions. Traditional methods of removing VOCs from the polluted air stream include adsorption onto activated carbons or zeolites and thermal combustion. These processes have strong limitations due to the difficult recovery of the adsorbent after regeneration and low durability, due to the high temperature of VOC degradation. Many advanced processes have been developed for the removal of VOCs from indoor air. Among the proposed technologies, catalytic oxidation is a promising approach for the degradation of pollutants to relatively harmless compounds or even to their complete oxidation to $\mathrm{H}_{2} \mathrm{O}$ and $\mathrm{CO}_{2}$ at low operating temperatures. Catalytic oxidation may be effectively used for the treatment of industrial VOCs resulting from processes using solvents, glue or insulating materials, and usually containing mono-aromatics BTEX (benzene, toluene, ethylbenzene, xylenes) and oxygenated compounds (acetone, ethanol, butanone, etc.). A series of catalysts have been evaluated for VOCs elimination. The most active catalysts particularly at low reaction temperatures (generally below $200{ }^{\circ} \mathrm{C}$ or even at room temperature in some cases) turn out to be noble metals ( $\mathrm{Pd}, \mathrm{Pt}, \mathrm{Au}$, and $\mathrm{Ag})$ dispersed on high surface area transition metal oxide supports $\left(\gamma-\mathrm{Al}_{2} \mathrm{O}_{3}, \mathrm{SiO}_{2}, \mathrm{TiO}_{2}, \mathrm{MnO}_{\mathrm{x}}\right.$, 
$\mathrm{CeO}_{2}$, etc.) $[69,70]$. The mixture of such oxide supports was shown to increase the dispersion of noble metals while reducing their loading. However, the cost of catalysts is a main obstacle for the industrial application of these VOCs removal processes.

Compared with the expensive and scarce noble metals, single or mixed metal oxides are currently extensively studied as alternatives for the catalytic oxidation of VOCs at low temperature. The developed transition metal oxides are mainly based on p-type semiconductors multivalent metal oxides due to the highly mobile chemisorbed oxygen species, thereby leading to enhanced activity $\left(\mathrm{Mn}_{3} \mathrm{O}_{4}, \mathrm{Mn}_{2} \mathrm{O}_{3}, \mathrm{MnO}_{2}, \mathrm{Co}_{3} \mathrm{O}_{4}, \mathrm{CeO}_{2}, \mathrm{MnOx}-\mathrm{CeO}_{2}, \mathrm{MnOx}-\mathrm{ZrO}_{2}, \mathrm{MnO}_{\mathrm{x}}-\mathrm{CuO}\right.$, etc.) [71,72]. Additionally, for a same chemical composition, the catalytic performances of metal oxides are also governed by their structure/morphology owing to preferential exposure of different active sites, and hence to variable surface oxygen vacancy densities [73]. Transition metal oxides also have distinct advantages over noble metal-based catalysts in the removal of halogenated VOCs, since they exhibit a higher chlorine resistance. As a perfect illustration of the fact that metal oxides can now be considered as a good alternative to noble metals, a Co-Al-Ce mixed oxide (referred to as CoAlCeO), synthesized by the hydrotalcite route, was studied for the total oxidation of industrial VOCs (toluene, butanone and VOCs mixtures) and compared to various palladium-based catalysts $\left(\mathrm{Pd} / \alpha-\mathrm{Al}_{2} \mathrm{O}_{3}\right.$, $\mathrm{Pd} / \mathrm{H}-\mathrm{FAU}, \mathrm{Pd} / \mathrm{CeO}_{2}$ and $\mathrm{Pd} / \gamma \mathrm{Al}_{2} \mathrm{O}_{3}$ ) [74]. Their catalytic properties were evaluated (considering the oxidation of by-products emitted from the process), highlighting the higher efficiency of the CoAlCeO mixed oxide than that of the Pd-based catalysts for the total oxidation of a VOCs mixture. Few studies have been reported on the catalytic oxidation of VOCs mixtures, especially at low concentration, even though this is a crucial step for industrial VOCs removal applications. Inhibition phenomena and molecules adsorption competition have been generally observed [75], which makes it difficult to find appropriate and efficient catalysts. Moreover, the oxidation mechanism of mixed VOCs is probably quite different from that of single VOC and more work should be done on these aspects. More efforts must also be devoted to the study of the reaction mechanisms of transition metal oxides by in situ characterization techniques to develop highly active non-precious catalysts for VOCs oxidation.

In addition to catalytic oxidation, photocatalysis has also been investigated for the decomposition of VOCs and other organic compounds on single or mixed metal oxides, such as $\mathrm{TiO}_{2}, \mathrm{~N}$-doped $\mathrm{TiO}_{2}$ and highly donor-doped layered perovskites catalysts [76-78]. When illuminated with UV or visible light, photocatalysts can generate strong active species able to decompose VOCs at low temperature. Simple reaction equipment is required, but problems of low selectivity for many VOCs photocatalysts have been reported [79].

With the aim of improving the removal efficiency of industrial VOCs and/or highly diluted VOCs, hybrid treatments combining catalytic oxidation with other technologies (ozonation, non-thermal plasma, etc.) are found to not only integrate the advantages of the individual technologies, but also are more effective to treat diverse and complex VOCs in the stream than do the single technology, while increasing the selectivity to $\mathrm{CO}_{2}$ [79]. For instance, catalytic oxidation of a large variety of VOCs have been carried out with ozone at low temperatures $\left(20-100{ }^{\circ} \mathrm{C}\right)$ over noble metal-based catalysts and transition metal oxides. Currently, many studies have been focused on unsupported or supported manganese oxides, since highly active oxygen species are formed by decomposition of $\mathrm{O}_{3}$ on MnOx oxides which can further oxidize VOCs at low temperatures [80-82]. Catalytic ozonation has been proven to be an alternative method particularly suited for the removal of low concentration VOCs pollution present in factory/workshop, meeting room, etc. However, one of the most important considerations is that highly efficient catalysts must be developed to avoid any potential secondary pollution. Catalysts capable of converting low VOC concentration at ambient conditions with a rational use of ozone should be found, so that the simultaneous removal of both pollutants and ozone occurs with no residual $\mathrm{O}_{3}$ at the end of the reaction.

The combination of non-thermal plasma (NTP) with catalysis has also attracted significant interest for VOCs decomposition, offering several advantages, namely energy efficiency, product selectivity and satisfactory carbon balance [83]. NTP consists of energetic electrons, ions, reactive radical species, 
neutral particles/molecules and UV photons $\left(\mathrm{e}-, \mathrm{O}^{\bullet}, \mathrm{HO}_{2} \bullet, \mathrm{HO}^{\bullet}, \mathrm{N}_{2}{ }^{\bullet}, \mathrm{O}_{3}\right.$, etc.). These species can decompose VOCs at ambient conditions, although the overall process is not selective to $\mathrm{CO}_{2}$. Such drawback can be overcome by using hybrid plasma processes, such as the combination of NTP with catalysis. One of the key parameters when referring to non-thermal plasma catalytic oxidation is the location of the catalyst with respect to the plasma reactor that should be carefully considered to achieve a synergistic effect [84]. The catalyst can be integrated either inside the plasma reactor (IPC (Inside Plasma Catalysis)) or downstream of the discharge region (PPC (Post Plasma Catalysis)), as shown in Figure 6.
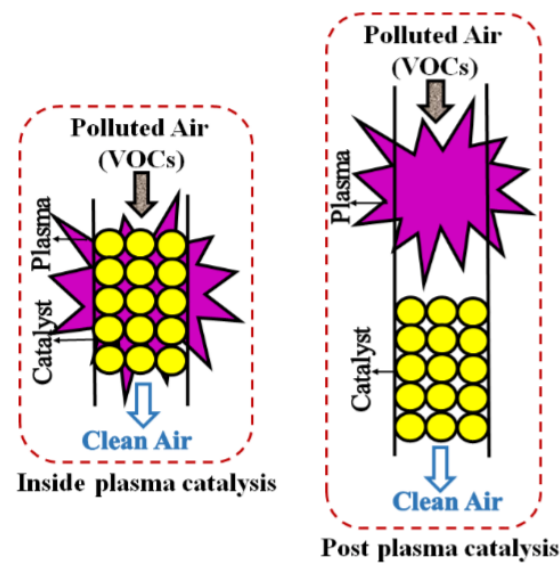

Figure 6. Schematic representation of the IPC (Inside Plasma Catalysis) and PPC (Post Plasma Catalysis) configurations [85].

The reaction mechanism of a zeolite-plasma hybrid system for the decomposition of toluene at room temperature was studied using gas and surface FTIR analyses [86]. The authors investigated different configurations of the zeolite hybrid reactor and showed that the main factor improving the reaction mechanism was the ozone generated in the gas phase by the plasma which reacted with toluene adsorbed onto the zeolite. Non-thermal plasma can also combine with photocatalysis to build up efficient hybrid treatments.

As described in Section 2.3, microwaves and ultrasound have been used as activation tools during the synthesis of transition metal oxides for VOCs degradation as well. For instance, it was reported that Co-Al hydrotalcite-like catalysts prepared by a microwave-assisted synthesis route were the most active in toluene oxidation compared to the corresponding oxides obtained by a traditional co-precipitation method, owing to a higher content of $\mathrm{Co}^{2+}$ species on the catalyst surface and hence to a greater amount of $\mathrm{O}_{\mathrm{II}}$ species available for the reaction [87].

In addition to supported noble metals, a variety of transition metal oxide-based catalysts $(\mathrm{Cu}, \mathrm{Co}$, $\mathrm{Mn}$, and $\mathrm{Fe}$ ) also proved to be highly efficient for depollution processes (CO, methane, $\mathrm{VOCs}, \mathrm{NO}_{\mathrm{x}}$, $\mathrm{NH}_{3}$ and wet air oxidation). Compared to single oxides, mixed oxides such as spinels, perovskites, hexaaluminates or derived from a hydrotalcite route, exhibit in some cases efficiencies as high as those of noble metals thanks to their high stability and oxygen mobility. The structure/morphology, structure defects and preferential exposure of active sites are also key parameters to control for maximizing the catalytic performances. In addition to the physical-chemical properties of the catalysts, the combine use of new activation methods (non-thermal plasma, ozonation, photo-oxidation, etc.) with catalytic oxidation already proved to enhance pollutant degradation (e.g., complex VOCs), along with high selectivity to $\mathrm{CO}_{2}$. Future research in this direction should also focus on the understanding of the reaction mechanisms involved in such integrated technologies. 


\subsection{Liquid Phase-Solid Catalyst Total Oxidation Reactions}

Wet air oxidation (WAO) is a process by which degradation of organic pollutants occurs in liquid-phase by oxidation with oxygen under pressure. WAO is employed to treat industrial waste waters at moderate temperatures $\left(180-315{ }^{\circ} \mathrm{C}\right)$ and at pressures from 2 to $15 \mathrm{MPa}$. However, lower energy requirements and significantly higher oxidation efficiencies can be achieved when adding homogeneous or heterogeneous catalysts. Such process is designated as catalytic wet air oxidation (CWAO). In addition to supported precious metal catalysts, oxide-based catalysts can also be used but care should be taken to avoid leaching of metallic ions. The treatment of toxic nitrogen-containing compounds, which are mainly produced in the chemical and pharmaceutical industries, is one of the major applications of a CWAO process. For instance, many studies have been done for the oxidation of aniline, which is often chosen as model molecule of a dye-industry pollutant. Particular attention has been paid to selectivity toward organic by-products (especially azo, nitroso and nitro compounds, phenolic compounds and carboxylic acids) and inorganic forms of nitrogen $\left(\mathrm{NH}_{4}{ }^{+}\right.$, $\mathrm{N}_{2}, \mathrm{NO}_{2}{ }^{-}$, and $\mathrm{NO}_{3}{ }^{-}$). Ammonia is one of the most refractory by-products, which unfortunately is formed during catalytic WAO of nitrogen-containing organic pollutants and is itself a pollutant. However, high selectivities to dinitrogen have been obtained on certain noble metal-based catalysts. Multifunctional catalysts have also been proposed for the treatment of nitrogenous organic compounds. More information on catalytic wet air oxidation processes for the treatment of refractory organic pollutants and industrial wastewaters can be found in recent review papers [88-90].

When the oxidation is performed with hydrogen peroxide instead of oxygen, the process is designated as wet peroxide oxidation (WPO) and the corresponding catalytic oxidation process is referred to as CWPO. Ozone can also be used as oxidant in ozonation processes, while UV irradiation is exploited in photocatalysis.

Advanced oxidation processes (AOPs) are near ambient temperature and pressure water treatment processes based on the in situ generation of highly reactive hydroxyl radicals $\left(\mathrm{HO}^{\bullet}\right)$ able to oxidize recalcitrant organic pollutants to smaller intermediates or to complete mineralization to $\mathrm{CO}_{2}$ and water. Formation of hydroxyl radicals can be achieved using various oxidants $\left(\mathrm{H}_{2} \mathrm{O}_{2}, \mathrm{O}_{3}\right.$, and UV) in chemical, sono-chemical, photo-chemical and electro-chemical processes and their combination [91]. Less conventional AOPs include ionizing radiation, non-thermal plasma and supercritical water oxidation. A schematic classification of advanced oxidation processes is presented in Figure 7. For example, photocatalysis may lead to the oxidation and the reduction of organic compound pollutants in water into intermediates containing oxygen, $\mathrm{CO}_{2}, \mathrm{H}_{2} \mathrm{O}$ and a mineral acid when a heteroatom such as nitrogen or chlorine is present. The photocatalytic reaction may be used in many domains such as the elimination of odor from drinking water, the degradation of oil spills in surface-water systems, or the degradation of harmful organic contaminants, such as herbicides, pesticides, and refractive dyes.

One of the most frequently used AOPs is based on the Fenton process, where $\mathrm{HO}^{\bullet}$ radicals are generated during activation of $\mathrm{H}_{2} \mathrm{O}_{2}$ by metallic cations (i.e., $\mathrm{Fe}^{2+}$ ). However, to overcome the major drawbacks of the homogeneous system (iron removal, sludge production, etc.), heterogeneous Fenton-type systems have been prepared to catalyze the oxidation of various organic pollutants in mild reaction conditions. A large variety of Fenton-like processes are available depending on the method used for the production of hydroxyl radicals, namely the photo-Fenton-like, electro-Fenton-like, sono-Fenton-like and microwave-Fenton-like processes, as well as their combined use, such as the photo-electro-Fenton-like, sono-photo-Fenton-like and sono-electro-Fenton-like processes, to name a few. The advances in the application of Fenton-like oxidation processes for the treatment of wastewater have been recently reviewed by several authors [91-93]. The main drawbacks of such Fenton-like processes is the leaching of iron species into the solution, which means that the real catalyst is the homogeneous species and the catalysts deactivate with time on stream. 


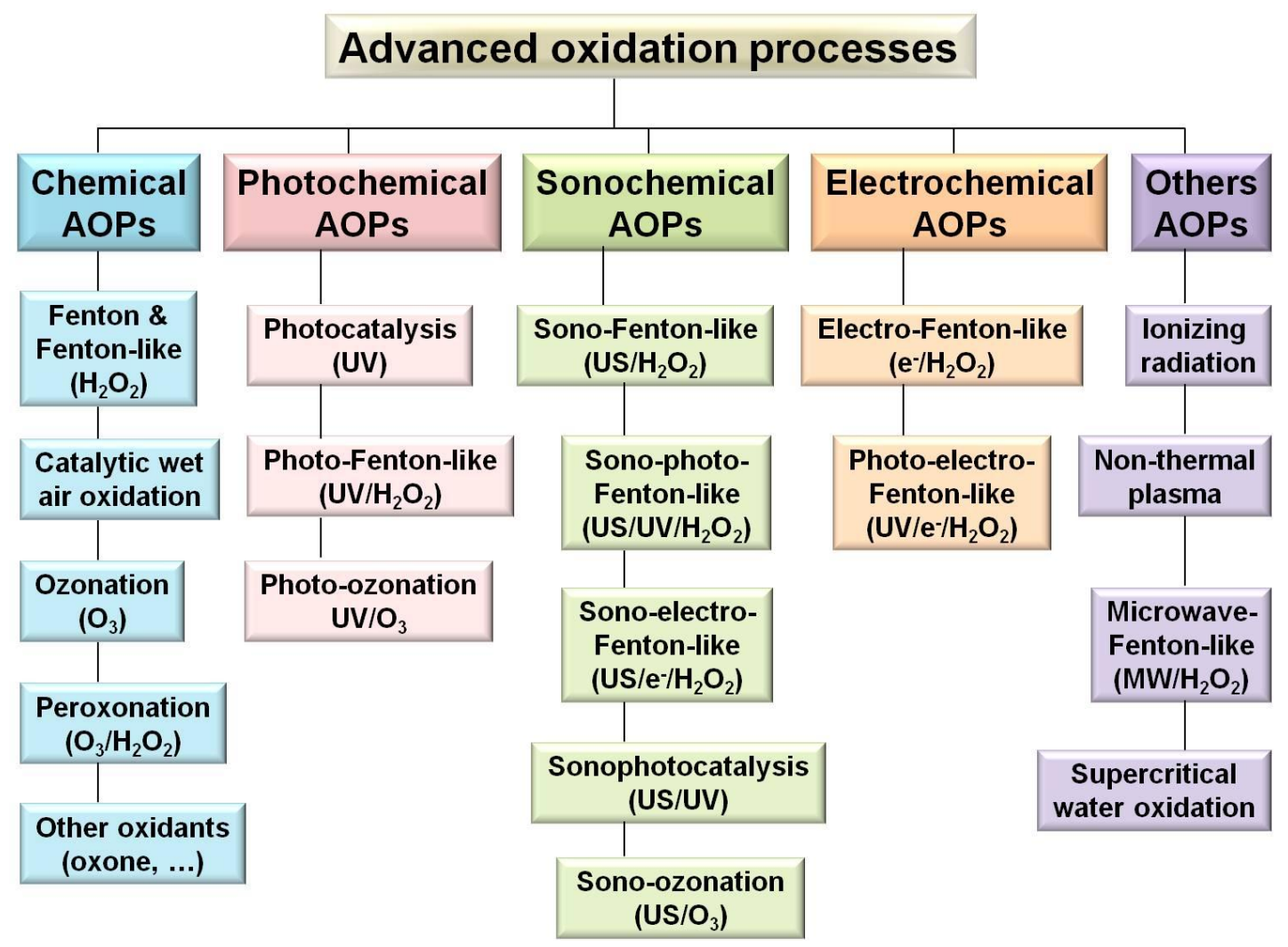

Figure 7. Classification of advanced oxidation processes. The nature of the catalysts used in these AOPs has not been mentioned for the sake of clarity.

The combination of sonocatalysis with photocatalysis has been widely investigated in the last fifteen years as AOP for the degradation of a large variety of organic pollutants in aqueous phase [56], such as phenolic compounds, dyes, pharmaceuticals, pesticides and textile industrial effluents [94]. The combined effects of such sonophotochemical process (see Section 2.3), coupled to the efficient use of a photocatalyst, result in an increased production of free radicals in aqueous solution and of cavitation bubbles, enhance mass transfer between the pollutants and the photocatalyst, as well as remove any impurities from its surface. Hence, an increase of the reaction rates of pollutants degradation is observed.

A novel method based on catalytic ozonation coupled to high-frequency ultrasound and Fe species was recently developed [95] for decomposing anti-inflammatory pharmaceutical ibuprofen (IBP) present in waste water. The $\mathrm{pH}$ value was found to be the most crucial parameter among the variables investigated in this sonocatalytic ozonation process (concentration of IBP, ozone flow rate, US power, $\mathrm{pH}$, and catalyst dosage). It determined the mass transfer, diffusion of ozone and organic solutes from the bulk liquid to the gas-liquid/liquid-solid interfaces, formation of reactive oxygen species which promoted Fenton-like reactions, as well as the reactivity of the Fe species. The oxidation and mineralization degree of IBP were highly enhanced in $40 \mathrm{~min}$ of reaction under simultaneous US $/ \mathrm{O}_{3} / \mathrm{Fe}$ conditions compared to single ultrasound irradiation (US/Fe) and ozonation $\left(\mathrm{O}_{3} / \mathrm{Fe}\right)$ processes.

In summary, many AOPs have been reported so far for the degradation of refractory compounds in liquid phase. Further investigations are however required to identify scale-up parameters including reactors design. 


\section{Conclusions}

In this review, we have provided several types of oxidation reactions (selective/partial or total, gas-solid and liquid-solid phases), of oxidation catalysts and of activation procedures, illustrated by case studies or industrial application, mainly gathered in the last two decades. It is well known that many oxidation reactions, particularly in selective oxidation domain, have been industrialized in the second part of the 20th century and beginning of this century for total oxidation. Gas solid oxidation reactions have been mainly studied and applied last century. However, with the increased environmental issues and legislation constraints, new processes or improved processes have been developed more recently. This is why depollution has been largely and widely studied in the past two or three decades and that liquid phase heterogeneous catalysis has been developed, particularly when biomass raw material products were available and wastewaters are to be more efficiently depolluted. We have also emphasized that selectivity is a major factor to look for in heterogeneous catalysis, which necessitate to control and avoid undesired by-products, particularly in industrial processes and in pharmaceutical and medical domains.

We have also shown that eco-compatible activation methods based on ultrasound and microwaves irradiations, grinding, and electro- and photo-activated processes offer challenging opportunities for the selective conversion of a library of alcohols and biomass-derived compounds, as well as for total oxidation reactions of pollutants in both gas phase and liquid phase. These non-thermal activation technologies often surpass the effects of conventional thermal conditions by increasing reaction rates, shortening reaction times, and improving activity and selectivity, while being cost and energy efficient. They represent a very challenging but quite promising domain for future research for a more sustainable world.

Author Contributions: Both authors have contributed equally to the writing and editing of the paper.

Funding: S.V. acknowledges financial support from the European Union (ERDF) and "Région Nouvelle Aquitaine".

Conflicts of Interest: The authors declare no conflict of interest.

\section{References}

1. Callahan, J.L.; Grasselli, R.K. A selectivity factor in vapor phase hydrocarbon oxidation catalysis. AIChE J. 1963, 9, 755-760. [CrossRef]

2. Brazdil, J.F. A critical perspective in the design and development of metal oxide catalysts for selective propylene ammoxidation and oxidation. Appl. Catal. A Gen. 2017, 543, 225-233. [CrossRef]

3. Brazdil, J.F. Selective oxidation in industry. In Heterogeneous Catalysis by Metal Oxides; Védrine, J.C., Ed.; Elsevier: Amsterdam, The Netherlands, 2018; pp. 455-502.

4. López Nieto, J.M.; Solsona, B. Gas phase heterogeneous partial oxidation reactions. In Heterogeneous Catalysis by Metal Oxides; Védrine, J.C., Ed.; Elsevier: Amsterdam, The Netherlands, 2018; pp. 211-286.

5. Dagnan, T.F. Industrial applications of metal oxide catalysts-An impressive past and a promising future. In Heterogeneous Catalysis by Metal Oxides; Védrine, J.C., Ed.; Elsevier: Amsterdam, The Netherlands, 2018; pp. 503-546.

6. Mars, P.; van Krevelen, D.W. Oxidation carried out by means of vanadium oxide catalysts. Chem. Eng. Sci. 1954, 3 (Suppl. 1), 41-49. [CrossRef]

7. Grasselli, R.K. Fundamental principles of selective heterogeneous oxidation catalysis. Top. Catal. 2002, 21, 79-88. [CrossRef]

8. Grasselli, R.K. Site isolation and phase cooperation: Two important concepts in selective oxidation catalysis: A retrospective. Catal. Today 2014, 238, 10-27. [CrossRef]

9. Védrine, J.C.; Fechete, I. Heterogeneous partial oxidation catalysis on metal oxides. CR Chim. 2016, 119, 1203-1225. [CrossRef]

10. Chu, W.; Luo, J.; Paul, S.; Liu, Y.; Khodakov, A.; Bordes, E. Synthesis and performance of vanadium-based catalysts for the selective oxidation of light alkanes. Catal. Today 2017, 298, 145-157. [CrossRef] 
11. Ivars, F.; López Nieto, J.M. Light alkanes oxidation: Targets reached and current challenges. In Advanced Methods and Processes on Oxidation Catalysis: From Laboratory to Industry; Cavani, F., Duprez, D., Eds.; Imperial College Press: London, UK, 2014; pp. 767-833.

12. López Nieto, J.M. Bifunctional $\mathrm{Mo}_{3} \mathrm{VO}_{x} / \mathrm{H}_{4} \mathrm{SiW}_{12} \mathrm{O}_{40} / \mathrm{Al}_{2} \mathrm{O}_{3}$ catalysts for one-step conversion of glycerol to acrylic acid: Catalyst structural evolution and reaction pathways. Appl. Catal. B Environ. 2015, 175, 1-12.

13. La Salvia, N.; Delgado, D.; Ruiz-Rodríguez, L.; Nadji, L.; Massó, A.; López Nieto, J.M. V- and Nb-containing bronzes catalysts for the aerobic transformation of ethanol and glycerol. Bulk and supported materials. Catal. Today 2017, 296, 2-9. [CrossRef]

14. Chieregato, A.; Soriano, M.D.; Basile, F.; Liosi, G.; Zamora, S.; Concepción, P.; Cavania, C.; López Nieto, J.M. One-pot glycerol oxidehydration to acrylic acid on multifunctional catalysts: focus on the influence of the reaction parameters in respect to the catalytic performance. Appl. Catal. B 2014, 150-151, 37-46. [CrossRef]

15. Kalevaru, V.N.; Dhachapally, N.; Martin, A. Catalytic performance of lanthanum vanadate catalysts in ammoxidation of 2-methylpyrazine. Catalysts 2016, 6, 10. [CrossRef]

16. Armstrong, R.D.; Hutchings, G.J.; Taylor, S.H. An overview of recent advances of the catalytic selective oxidation of ethane to oxygenates. Catalysts 2016, 6, 71. [CrossRef]

17. Liu, F.; Wang, H.; Sapi, A.; Tatsumi, H.; Zherebetskyy, D.; Han, H.-L.; Carl, L.M.; Somorjai, G.A. Molecular orientations change reaction kinetics and mechanism: A review on catalytic alcohol oxidation in gas phase and liquid phase on size-controlled Pt nanoparticles. Catalysts 2018, 8, 226. [CrossRef]

18. Galadima, A.; Muraza, O. A review on glycerol valorization to acrolein over solid acid catalysts. J. Taiwan Inst. Chem. Eng. 2016, 67, 29-44. [CrossRef]

19. Cespi, D.; Passarini, F.; Mastragostino, G.; Vassura, I.; Larocca, S.; Iaconi, A.; Chieregato, A.; Dubois, J.-L.; Cavani, F. Glycerol as feedstock in the synthesis of chemicals: A life cycle analysis for acrolein production. Green Chem. 2015, 17, 343-355. [CrossRef]

20. Katryniok, B.; Kimura, H.; Skrzyńska, E.; Girardon, J.S.; Fongarland, P.; Capron, M.; Dumeignil, F. Selective catalytic oxidation of glycerol: Perspectives for high value chemicals. Green Chem. 2011, 13, 1960-1979. [CrossRef]

21. Villa, A.; Dimitratos, N.; Chan-Thaw, C.E.; Hammond, C.; Prati, L.; Hutchings, G.J. Glycerol oxidation using gold-containing catalysts. Acc. Chem. Res. 2015, 48, 1403-1412. [CrossRef] [PubMed]

22. Liang, D.; Gao, J.; Sun, H.; Chen, P.; Hou, Z.; Zheng, X. Selective oxidation of glycerol with oxygen in a base-free aqueous solution over MWNTs supported Pt catalysts. Appl. Catal. B 2011, 106, 423-432. [CrossRef]

23. Xue, W.; Wang, Z.; Liang, Y.; Xu, H.; Liu, L.; Dong, J. Promoting role of bismuth on hydrotalcite-supported platinum catalysts in aqueous phase oxidation of glycerol to dihydroxyacetone. Catalysts 2018, 8, 20. [CrossRef]

24. Li, X.; Zhang, Y. Highly efficient process for the conversion of glycerol to acrylic acid via gas phase catalytic oxidation of an allyl alcohol intermediate. ACS Catal. 2016, 6, 143-150. [CrossRef]

25. Chieregato, A.; Basile, F.; Concepción, P.; Guidetti, S.; Liosi, G.; Soriano, M.D.; Trevisianut, C.; Cavani, F.; López Nieto, J.M. Glycerol oxidehydration into acrolein and acrylic acid over $\mathrm{W}-\mathrm{V}-\mathrm{Nb}-\mathrm{O}$ bronzes with hexagonal structure. Catal. Today 2012, 197, 58-75. [CrossRef]

26. Shen, L.; Yin, H.; Wang, A.; Lu, X.; Zhang, C. Gas phase oxidehydration of glycerol to acrylic acid over Mo/V and W/V oxide catalysts. Chem. Eng. J. 2014, 244, 168-177. [CrossRef]

27. Pinna, F.; Olivo, A.; Trevisan, V.; Manegazzo, F.; Signoretto, M.; Manzoli, M.; Boccuzzi, F. The effects of gold nanosize for the exploitation of furfural by selective oxidation. Catal. Today 2013, 203, 196-201. [CrossRef]

28. Ampelli, C.; Centi, G.; Genovese, C.; Papanikolaou, G.; Pizzi, R.; Perathoner, S.; van Putten, R.-J.; Schouten, K.J.P.; Gluhoi, A.C.; van der Waal, J.C. A comparative catalyst evaluation for the selective oxidative esterification of furfural. Top. Catal. 2016, 59, 1659-1667. [CrossRef]

29. Menegazzo, F.; Signoretto, M.; Pinna, F.; Manzoli, M.; Aina, V.; Cerrato, G.; Boccuzzi, F. Oxidative esterification of renewable furfural on gold-based catalysts: which is the best support? J. Catal. 2014, 309, 241-247. [CrossRef]

30. Bozell, J.J.; Petersen, G.R. Technology development for the production of biobased products from biorefinery carbohydrates-The US department of energy's “Top 10" revisited. Green Chem. 2010, 12, 539-554. [CrossRef]

31. Deng, J.; Song, H.-J.; Cui, M.-S.; Du, Y.-P.; Fu, Y. Aerobic oxidation of hydroxymethylfurfural and furfural by using heterogeneous $\mathrm{Co}_{\mathrm{x}} \mathrm{O}_{\mathrm{y}}-\mathrm{N} @ \mathrm{C}$ catalysts. ChemSusChem 2014, 7, 3334-3340. [CrossRef] [PubMed] 
32. Ardemani, L.; Cibin, G.; Dent, A.J.; Isaacs, M.A.; Kyriakou, G.; Lee, A.F.; Parlett, C.M.A.; Parry, S.A.; Wilson, K. Solid base catalysed 5-HMF oxidation to 2,5-FDCA over Au/hydrotalcites: fact or fiction? Chem. Sci. 2015, 6, 4940-4945. [CrossRef] [PubMed]

33. Neaţu, F.; Marin, R.S.; Florea, M.; Petrea, M.; Pavel, O.D.; Pârvulescu, V.I. Selective oxidation of 5-hydroxymethyl furfural over non-precious metal heterogeneous catalysts. Appl. Catal. B 2016, 180, 751-757. [CrossRef]

34. Wang, Y.; Jin, F.; Sasaki, M.; Wang, F.; Jing, Z.; Goto, M. Selective conversion of glucose into lactic acid and acetic acid with copper oxide under hydrothermal conditions. AIChE J. 2013, 59, 2096-2104. [CrossRef]

35. Yang, X.; Yang, L.; Fan, W.; Lin, H. Effect of redox properties of $\mathrm{LaCoO}_{3}$ perovskite catalyst on production of lactic acid from cellulosic biomass. Catal. Today 2016, 269, 56-64. [CrossRef]

36. Rodenas, Y.; Mariscal, R.; Fierro, J.L.G.; Martín Alonso, D.; Dumesic, J.A.; López Granados, M. Improving the production of maleic acid from biomass: TS-1 catalysed aqueous phase oxidation of furfural in the presence of $\gamma$-valerolactone. Green Chem. 2018, 20, 2845-2856. [CrossRef]

37. Deng, H.; Lin, L.; Liu, S. Catalysis of Cu-doped Co-based perovskite-type oxide in wet oxidation of lignin to produce aromatic aldehydes. Energy Fuels 2010, 24, 4797-4802. [CrossRef]

38. Farrusseng, D. (Ed.) Metal-organic frameworks: applications from catalysis to gas storage; Wiley-VCH: Weinheim, Germany, 2011.

39. Du, D.Y.; Qin, J.S.; Li, S.L.; Su, Z.M.; Lan, Y.Q. Recent advances in porous polyoxometalate-based metal-organic framework materials. Chem. Soc. Rev. 2014, 43, 4615-4632. [CrossRef] [PubMed]

40. Kholdeeva, O.A. Liquid-phase selective oxidation catalysis with metal-organic frameworks. Catal. Today 2016, 278, 22-29. [CrossRef]

41. Hill, C.L.; Kholdeeva, O.A. Liquid Phase Oxidation via Heterogeneous Catalysis: Organic Synthesis and Industrial Applications; Clerici, M.G., Kholdeeva, O.A., Eds.; Wiley-VCH: Weinheim, Germany, 2013; pp. 263-319.

42. Salomon, W.; Roch-Marchal, C.; Mialane, P.; Rouschemeyer, P.; Serre, C.; Haouas, M.; Taulelle, F.; Yang, S.; Ruhlmann, L.; Dolbecq, A. Immobilization of polyoxometalates in the Zr-based metal organic framework UiO-67. Chem. Commun. 2015, 51, 2972-2975. [CrossRef] [PubMed]

43. Edwards, J.K.; Ntainjua, E.; Carley, A.F.; Herzing, A.A.; Kiely, C.J.; Hutchings, G.J. Direct synthesis of $\mathrm{H}_{2} \mathrm{O}_{2}$ from $\mathrm{H}_{2}$ and $\mathrm{O}_{2}$ over gold, palladium and gold-palladium catalysts supported on acid pretreated $\mathrm{TiO}_{2}$. Angew. Chem. Int. Ed. 2009, 48, 8512-8515. [CrossRef] [PubMed]

44. Selinsek, M.; Deschner, B.J.; Doronkin, D.E.; Sheppard, T.L.; Grunwaldt, J.D.; Dittmeyer, R. Revealing the structure and mechanism of palladium during direct synthesis of hydrogen peroxide in continuous flow using operando spectroscopy. ACS Catal. 2018, 8, 2546-2557. [CrossRef]

45. Martina, K.; Manzoli, M.; Calcio Gaudino, E.; Cravotto, G. Eco-friendly physical activation methods for Susuki-Miyaura reactions. Catalysts 2017, 7, 98. [CrossRef]

46. Sylla-Iyarreta Veitía, M.; Ferroud, C. New activation methods used in green chemistry for the synthesis of high added value molecules. Int. J. Energy Environ. Eng. 2015, 6, 37-46. [CrossRef]

47. Behling, R.; Chatel, G.; Valange, S. Sonochemical oxidation of vanillyl alcohol to vanillin in the presence of a cobalt oxide catalyst under mild conditions. Ultrason. Sonochem. 2017, 36, 27-35. [CrossRef] [PubMed]

48. Maleki, A. Green oxidation protocol: Selective conversions of alcohols and alkenes to aldehydes, ketones and epoxides by using a new multiwall carbon nanotube based hybrid nanocatalyst via ultrasound irradiation. Ultrason. Sonochem. 2018, 40, 460-464. [CrossRef] [PubMed]

49. Domini, C.E.; Álvarez, M.B.; Silbestri, G.F.; Cravotto, G.; Cintas, P. Merging metallic catalysts and sonication: A periodic table overview. Catalysts 2017, 7, 121. [CrossRef]

50. Qu, C.; Kaneko, M.; Kashimura, K.; Tanaka, K.; Ozawa, S.; Watanabe, T. Direct production of vanillin from wood particles by copper oxide-peroxide reaction promoted by electric and magnetic fields of microwaves. ACS Sustain. Chem. Eng. 2017, 5, 11551-11557. [CrossRef]

51. Horie, K.; Barón, M.; Fox, R.B.; He, J.; Hess, M.; Kahovec, J.; Kitayama, T.; Kubisa, P.; Maréchal, E.; Mormann, W.; et al. Definitions of terms relating to reactions of polymers and to functional polymeric materials (IUPAC Recommendations 2003). Pure Appl. Chem. 2004, 76, 889-906. [CrossRef]

52. Porcheddu, A.; Colacino, E.; Cravotto, G.; Delogu, F.; De Luca, L. Mechanically induced oxidation of alcohols to aldehydes and ketones in ambient air: Revisiting TEMPO-assisted oxidations. Beilstein J. Org. Chem. 2017, 13, 2049-2055.00E9. [CrossRef] [PubMed] 
53. Simões, M.; Baranton, S.; Coutanceau, C. Electrochemical valorisation of glycerol. ChemSusChem 2012, 5, 2106-2124. [CrossRef] [PubMed]

54. Xiao, H.; Wu, M.; Zhao, G. Electrocatalytic oxidation of cellulose to gluconate on carbon aerogel supported gold nanoparticles anode in alkaline medium. Catalysts 2016, 6, 5. [CrossRef]

55. Colmenares, J.C.; Luque, R. Heterogeneous photocatalytic nanomaterials: propects and challenges in selective transformation of biomass-derived compounds. Chem. Soc. Rev. 2014, 43, 765-778. [CrossRef] [PubMed]

56. Chatel, G.; Valange, S.; Behling, R.; Colmenares, J.C. A combined approach using sonochemistry and photocatalysis: How to apply sonophotocatalysis for biomass conversion? ChemCatChem 2017, 9, 2615-2621. [CrossRef]

57. Hinman, J.J.; Suslick, K.S. Nanostructured materials synthesis using ultrasound. Top. Curr. Chem. (Z) 2017, 375, 12. [CrossRef] [PubMed]

58. Mansoli, M.; Bonelli, B. Microwave, ultrasound, and mechanochemistry: unconventional tools that are used to obtain "smart" catalysts for $\mathrm{CO}_{2}$ hydrogenation. Catalysts 2018, 8, 262. [CrossRef]

59. Muñoz-Batista, M.J.; Rodriguez-Padron, D.; Puente-Santiago, A.R.; Luque, R. Mechanochemistry: toward sustainable design of advanced nanomaterials for electrochemical energy storage and catalytic applications. ACS Sustain. Chem. Eng. 2018, 6, 9530-9544. [CrossRef]

60. Meng, L.-Y.; Wang, B.; Ma, M.-G.; Lin, K.-L. The progress of microwave-assisted hydrothermal method in the synthesis of functional nanomaterials. Mater. Today Chem. 2016, 1-2, 63-83. [CrossRef]

61. Magdziarz, A.; Colmenares, J.C. In situ coupling of ultrasound to electro- and photo-deposition methods for materials synthesis. Molecules 2017, 22, 216. [CrossRef] [PubMed]

62. Dharmarathna, S.; King'ondu, C.K.; Pedrick, W.; Pahalagedara, L.; Suib, S.L. Direct sonochemical synthesis of manganese octahedral molecular sieve (OMS-2) nanomaterials using cosolvent systems, their characterization, and catalytic applications. Chem. Mater. 2012, 24, 705-712. [CrossRef]

63. Amaniampong, P.N.; Trinh, Q.T.; Varghese, J.J.; Behling, R.; Valange, S.; Mushrif, S.H.; Jérôme, F. Unraveling the mechanism of the oxidation of glycerol to dicarboxylic acids over a sonochemically synthesized copper oxide catalyst. Green Chem. 2018, 20, 2730-2741. [CrossRef]

64. Xu, C.; De, S.; Balu, A.M.; Ojeda, M.; Luque, R. Mechanochemical synthesis of advanced nanomaterials for catalytic applications. Chem. Commun. 2015, 51, 6698-6713. [CrossRef] [PubMed]

65. Wang, C.L.; Sun, L.; Yun, H.; Li, J.; Lai, Y.K.; Lin, C.J. Sonoelectrochemical synthesis of highly photoelectrochemically active $\mathrm{TiO}_{2}$ nanotubes by incorporating CdS nanoparticles. Nanotechnology 2009, 20, 295601. [CrossRef] [PubMed]

66. Magdziarz, A.; Colmenares, J.C.; Chernyayeva, O.; Kurzydlowski, K.; Grzonka, J. Iron-containing titania photocatalyst prepared by the sonophotodeposition method for the oxidation of benzyl alcohol. ChemCatChem 2016, 8, 536-539. [CrossRef]

67. Bion, N.; Can, F.; Courtois, X.; Duprez, D. Transition metal oxides for combustion and depollution processes. In Heterogeneous Catalysis by Metal Oxides; Védrine, J.C., Ed.; Elsevier: Amsterdam, The Netherlands, 2018; pp. 287-352.

68. Xie, X.; Li, Y.; Liu, Z.-Q.; Haruta, M.; Shen, W. Low-temperature oxidation of $\mathrm{CO}$ catalysed by $\mathrm{Co}_{3} \mathrm{O}_{4}$ nanorods. Nature 2009, 458, 746-749. [CrossRef] [PubMed]

69. Santos, V.P.; Carabineiro, S.A.C.; Tavares, P.B.; Pereira, M.F.R.; Órfão, J.J.M.; Figueiredo, J.L. Oxidation of CO, ethanol and toluene over $\mathrm{TiO}_{2}$ supported noble metal catalysts. Appl. Catal. B 2010, 99, 198-205. [CrossRef]

70. Scirè, S.; Liotta, L.F. Supported gold catalysts for the total oxidation of volatile organic compounds. Appl. Catal. B 2012, 125, 222-246. [CrossRef]

71. Huang, H.; Xu, Y.; Feng, Q.; Leung, D.Y.C. Low temperature catalytic oxidation of volatile organic compounds: A review. Catal. Sci. Technol. 2015, 5, 2649-2669. [CrossRef]

72. Garcia, T.; Solsona, B.; Taylor, S.H. The catalytic oxidation of hydrocarbon volatile organic compounds. In Advanced Methods and Processes on Oxidation Catalysis: From Laboratory to Industry; Duprez, D., Cavani, F., Eds.; Imperial College Press: London, UK, 2014; pp. 51-90.

73. Wang, F.; Dai, H.; Deng, J.; Bai, G.; Ji, K.; Liu, Y. Manganese oxides with rod-, wire-, tube-, and flower-like morphologies: highly effective catalysts for the removal of toluene. Environ. Sci. Technol. 2012, 46, 4034-4041. [CrossRef] [PubMed] 
74. Brunet, J.; Genty, E.; Barroo, C.; Cazier, F.; Poupin, C.; Siffert, S.; Thomas, D.; De Weireld, G.; Visart de Bocarmé, T.; Cousin, R. The CoAlCeO mixed oxide: An alternative to palladium-based catalysts for total oxidation of industrial VOCs. Catalysts 2018, 8, 64. [CrossRef]

75. Burgos, N.; Paulis, M.; Mirari Antxustegi, M.; Montes, M. Deep oxidation of VOC mixtures with platinum supported on $\mathrm{Al}_{2} \mathrm{O}_{3} / \mathrm{Al}$ monoliths. Appl. Catal. B Environ. 2002, 38, 251-258. [CrossRef]

76. Pena, M.A.; Fierro, J.L.G. Chemical structures and performance of perovskite oxides. Chem. Rev. 2001, 101, 1981-2018. [CrossRef] [PubMed]

77. Kumar, S.G.; Gomathi, L.D. Review on modified $\mathrm{TiO}_{2}$ photocatalysis under UV/visiblelight: Selected results and related mechanisms on interfacial charge carrier transfer dynamics. J. Phys. Chem. A 2015, 115, 13211-13241. [CrossRef] [PubMed]

78. Yang, G.; Jiang, Z.; Shi, H.; Xiao, T.; Yan, Z. Review on preparation of highly visible-light active N-doped $\mathrm{TiO}_{2}$ photocatalyst. J. Mater. Chem. 2010, 20, 5301-5309. [CrossRef]

79. Zhang, Z.; Jiang, Z.; Shagguan, W. Low-temperature catalysis for VOCs removal in technology and application: A state-of-the-art review. Catal. Today 2016, 264, 270-278. [CrossRef]

80. Rezaei, E.; Soltan, J. Low temperature oxidation of toluene by ozone over $\mathrm{MnO}_{\mathrm{x}} / \gamma$-alumina and $\mathrm{MnO}_{\mathrm{x}} / \mathrm{MCM}-41$ catalysts. Chem. Eng. J. 2012, 198-199, 482-490. [CrossRef]

81. Zhao, D.-Z.; Shi, C.; Li, X.-S.; Zhu, A.-M.; Jang, B.-W. Enhanced effect of water vapor on complete oxidation of formaldehyde in air with ozone over $\mathrm{MnO}_{\mathrm{x}}$ catalysts at room temperature. J. Hazard. Mater. 2012, 239-240, 362-369. [CrossRef] [PubMed]

82. Einaga, H.; Ogata, A. Benzene oxidation with ozone over supported manganese oxide catalysts: effect of catalyst support and reaction conditions. J. Hazard. Mater. 2009, 164, 1236-1241. [CrossRef] [PubMed]

83. Ye, Z.; Giraudon, J.-M.; De Geyter, N.; Morent, R.; Lamonier, J.-F. The design of $\mathrm{MnO}_{\mathrm{x}}$ based catalyst in post-plasma catalysis configuration for toluene abatement. Catalysts 2018, 8, 91. [CrossRef]

84. Trinh, Q.H.; Mok, Y.S. Non-thermal plasma combined with cordierite-supported Mn and Fe based catalysts for the decomposition of diethylether. Catalysts 2015, 5, 800-814. [CrossRef]

85. Sultana, S.; Vandenbroucke, A.M.; Leys, C.; De Geyter, N.; Morent, R. Abatement of VOCs with alternate adsorption and plasma-assisted regeneration: a review. Catalysts 2015, 5, 718-746. [CrossRef]

86. Teramoto, Y.; Kim, H.-H.; Negishi, N.; Ogata, A. The role of ozone in the reaction mechanism of a bare zeolite-plasma hybrid system. Catalysts 2015, 5, 838-850. [CrossRef]

87. Genty, E.; Brunet, J.; Poupin, C.; Casale, S.; Capelle, S.; Massiani, P.; Siffert, S.; Cousin, R. Co-Al mixed oxides prepared via $\mathrm{LDH}$ route using microwaves or ultrasound: application for catalytic toluene total oxidation. Catalysts 2015, 5, 851-867. [CrossRef]

88. Arena, F.; Di Chio, R.; Gumina, B.; Spadaro, L.; Trunfio, G. Recent advances on wet air oxidation catalysts for treatment of industrial wastewaters. Inorg. Chim. Acta 2015, 431, 101-109. [CrossRef]

89. Jing, G.; Luan, M.; Chen, T. Progress of catalytic wet air oxidation technology. Arabian J. Chem. 2016, 9 , S1208-S1213. [CrossRef]

90. Fu, J.; Kyzas, G.Z. Wet air oxidation for the decolorization of dye wastewater: An overview of the last two decades. Chin. J. Catal. 2014, 35, 1-7. [CrossRef]

91. Divyapriya, G.; Nambi, I.M.; Senthilnathan, J. Nanocatalysts in Fenton based advanced oxidation process for water and wastewater treatment. J. Bionanosci. 2016, 10, 356-368. [CrossRef]

92. Wang, N.; Zheng, T.; Zhang, G.; Wang, P. A review on Fenton-like processes for organic wastewater treatment. J. Environ. Chem. Eng. 2016, 4, 762-787. [CrossRef]

93. Babuponnusami, A.; Muthukumar, K. A review on Fenton and improvements to the Fenton process for wastewater treatment. J. Environ. Chem. Eng. 2014, 2, 557-572. [CrossRef]

94. Mahajan, V.K.; Sonwane, G.H. Effective degradation and mineralization of real textile effluent by sonolysis, photocatalysis, and sonophotocatalysis using ZnO nano catalyst. Nanochem. Res. 2016, 1, 258-263.

95. Ziylan, A.; Ince, N.H. Catalytic ozonation of ibuprofen with ultrasound and Fe-based catalysts. Catal. Today 2015, 240, 2-8. [CrossRef]

(C) 2018 by the authors. Licensee MDPI, Basel, Switzerland. This article is an open access article distributed under the terms and conditions of the Creative Commons Attribution (CC BY) license (http:/ / creativecommons.org/licenses/by/4.0/). 